\title{
A joint procedural position statement on imaging in cardiac sarcoidosis: from the Cardiovascular and Inflammation \& Infection Committees of the European Association of Nuclear Medicine, the European Association of Cardiovascular Imaging, and the American Society of Nuclear Cardiology
}

Riemer H. J. A. Slart, ${ }^{\text {a,b }}$ Andor W. J. M. Glaudemans, ${ }^{a}$ Patrizio Lancellotti, ${ }^{c, d}$ Fabien Hyafil, ${ }^{\text {e,f }}$ Ron Blankstein, ${ }^{\text {,h }}$ Ronald G. Schwartz, ${ }^{\mathrm{i}, \mathrm{j}}$ Wael A. Jaber, ${ }^{\mathrm{k}}$ Raymond Russell, ${ }^{1}$ Alessia Gimelli, ${ }^{\mathrm{m}}$ François Rouzet, ${ }^{\mathrm{e}}$ Marcus Hacker, ${ }^{\mathrm{n}}$ Olivier Gheysens, ${ }^{\text {o,p }}$ Sven Plein, ${ }^{\mathrm{q}}$ Edward J. Miller, ${ }^{\mathrm{r}}$ Sharmila Dorbala, ${ }^{\mathrm{g}, \mathrm{h}}$ and Erwan Donal, ${ }^{\text {s,t }}$ Document Reading Group

a Department of Nuclear Medicine and Molecular Imaging, University of Groningen, University Medical Center Groningen, Groningen, The Netherlands

b Department of Biomedical Photonic Imaging, University of Twente, Enschede, The Netherlands

c Department of Cardiology, GIGA-Cardiovascular Sciences, University Hospital Sart Tilman, Liège, Belgium

d Gruppo Villa Maria Care and Research, Anthea Hospital, Bari, Italy

e Department of Nuclear Medicine, Centre Hospitalier Universitaire Bichat, Département Hospitalo-Universitaire FIRE, Inserm 1148, Assistance Publique - Hôpitaux de Paris, Université Paris Diderot, Paris, France

f Department of Nuclear Medicine Klinikum rechts der Isar, Technische Universität München, Munich, Germany

g Division of Nuclear Medicine and Molecular Imaging, Department of Radiology, Brigham and Women's Hospital, Boston, MA

h Division of Cardiovascular Medicine, Department of Medicine, Brigham and Women's Hospital, Boston, MA

i Cardiology Division, Department of Medicine, University of Rochester Medical Center, Rochester, NY

j Nuclear Medicine Division, Department of Imaging Sciences, University of Rochester Medical Center, Rochester, NY

k Cleveland Clinic Lerner College of Medicine, Heart and Vascular Institute, Cleveland Clinic, Cleveland, $\mathrm{OH}$

Electronic supplementary material The online version of this article (doi:10.1007/s12350-017-1043-4) contains supplementary material, which is available to authorized users.

Sharmila Dorbala and Erwan Donal have contributed equally to this study.

This article is being published concurrently in the European Heart Journal: Cardiovascular Imaging (10.1093/ehjci/jex146) and the Journal of Nuclear Cardiology.
Reprint requests: Riemer H. J. A. Slart, Department of Nuclear Medicine and Molecular Imaging, University of Groningen, University Medical Center Groningen, Hanzeplein 1, P.O. Box 30001, 9700 RB, Groningen, The Netherlands; r.h.j.a.slart@umcg.nl J Nucl Cardiol 2018;25:298-319.

$1071-3581 / \$ 34.00$

Copyright () 2017 European Association of Nuclear Medicine, the European Association of Cardiovascular Imaging, and the American Society of Nuclear Cardiology. 
I Cardiovascular Institute, Rhode Island Hospital, Alpert School of Medicine of Brown University, Providence, RI

${ }^{m}$ Fondazione Toscana/CNR Gabriele Monasterio, Pisa, Italy

n Division of Nuclear Medicine, Department of Biomedical Imaging and Image-guided Therapy, Medical University Vienna, Vienna, Austria

- Nuclear Medicine and Molecular Imaging, University Hospitals Leuven, Louvain, Belgium

P Department of Imaging and Pathology, KU Leuven, Louvain, Belgium

q Leeds Institute of Cardiovascular and Metabolic Medicine, University of Leeds, Leeds, UK

r Section of Cardiovascular Medicine, Yale School of Medicine, New Haven, CT

s Service de Cardiologie, et CIC-IT INSERM 1414, CHU Rennes, Rennes, France

t LTSI, Université de Rennes 1 - INSERM, UMR 1099, Rennes, France

doi:10.1007/s12350-017-1043-4

Document Reading Group

\section{Roberto Sciagra ${ }^{\mathrm{a}}$ Jan Bucerius $\mathrm{s}^{\mathrm{b}, \mathrm{c}, \mathrm{d}}$ \\ Hein J. Verberne $\mathrm{e}^{\mathrm{e}}$ \\ Oliver Lindner ${ }^{\mathrm{f}}$ \\ Christopher Übleis ${ }^{g}$ \\ Denis Agostini ${ }^{\text {h }}$ \\ Alberto Signore ${ }^{i}$ \\ Thor Edvardsen ${ }^{j}$}

\author{
Danilo Negliak \\ Rob S. Beanlands' \\ Marcelo Di Carli ${ }^{\mathrm{m}, \mathrm{n}}$ \\ Panithaya Chareonthaitawee ${ }^{\circ}$ \\ Vasken Dilsizian $^{\mathrm{p}}$ \\ Prem Soman ${ }^{q}$ \\ Gilbert Habib ${ }^{r}$
}

\footnotetext{
${ }^{a}$ Nuclear Medicine Unit, Department of Experimental and Clinical Biomedical Sciences, University of Florence, Florence, Italy ${ }^{b}$ Department of Nuclear Medicine, Maastricht University Medical Center, Maastricht, The Netherlands ${ }^{\circ}$ Cardiovascular Research Institute Maastricht (CARIM), Maastricht University Medical Center, Maastricht, The Netherlands ${ }^{\mathrm{d}}$ Department of Nuclear Medicine, University Hospital RWTH Aachen, Aachen, Germany

e Department of Nuclear Medicine, Academic Medical Center, Amsterdam, The Netherlands

${ }^{\mathrm{f}}$ Institute of Radiology Nuclear Medicine and Molecular Imaging, Heart and Diabetes Center NRW, Bad Oeynhausen, Germany

g Department of Clinical Radiology, Ludwig-Maximilians Universität München, Munich, Germany

${ }^{\mathrm{h}}$ Department of Nuclear Medicine, CHU Cote de Nacre, Caen, France

iNuclear Medicine Unit, Department of Medical-Surgical Sciences and of Translational Medicine, Faculty of Medicine and Psychology, 'Sapienza' University of Roma, Rome, Italy

'Department of Cardiology, Oslo University Hospital, Rikshospitalet and University of Oslo, Oslo, Norway

${ }^{\mathrm{k}}$ Fondazione Toscana/CNR Gabriele Monasterio, Pisa, Italy

'Division of Cardiology, Department of Medicine, University of Ottawa Heart Institute, Ottawa, Canada

mivision of Nuclear Medicine and Molecular Imaging, Department of Radiology, Department of Medicine, Brigham and Women's Hospital, Boston, MA, USA

${ }^{n}$ Division of Cardiovascular Medicine, Department of Medicine, Brigham and Women's Hospital, Boston, MA, USA

${ }^{\circ}$ Department of Cardiovascular Diseases, Mayo Clinic, Rochester, MN, USA

${ }^{\mathrm{P} D}$ Department of Diagnostic Radiology and Nuclear Medicine, University of Maryland School of Medicine, Baltimore, MD, USA

${ }^{\mathrm{q}}$ Division of Cardiology Heart and Vascular Institute, University of Pittsburgh Medical Center, A-429 Scaife Hall 200 Lothrop Street, Pittsburgh, PA, 15213, USA

'Department of Cardiology, Aix-Marseille Université, Marseille 13284, France La Timone Hospital, 13005, Marseille, France
} 


\section{EACVI Reviewers:}

$\begin{array}{ll}\text { This document was reviewed by members of the EACVI Scientific Documents Committee for 2014-2016 and } \\ \text { 2016-2018: } & \text { Bernhard Gerber } \\ \text { Victoria Delgado } & \text { Kristina Haugaa } \\ \text { Nuno Cardim } & \text { Massimo Lombardi } \\ \text { Bernard Cosyns } & \text { Pier Giorgio Masci } \\ \text { Frank Flachskampf } & \end{array}$

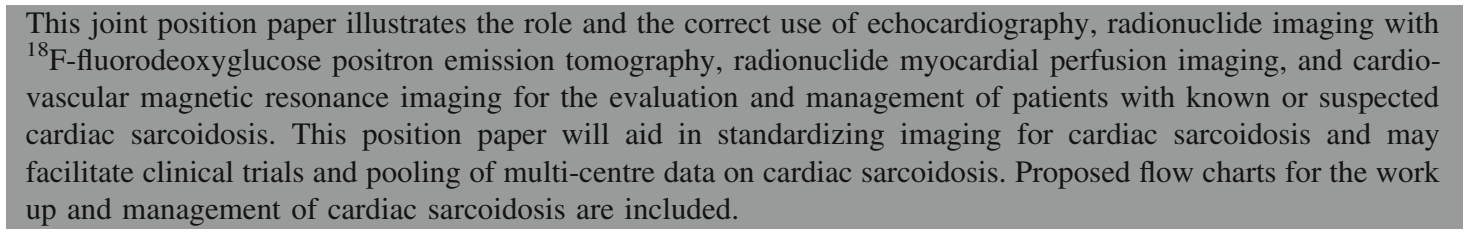

\section{PREAMBLE}

This procedural position paper on the use of imaging in the management of patients with known or suspected cardiac sarcoidosis has been developed under the auspices of the Cardiovascular and the Inflammation and Infection Committee of the European Association of Nuclear Medicine, the European Association of Cardiovascular Imaging of the European Society of Cardiology, and the American Society of Nuclear Cardiology, highlighting the close collaboration between the societies on this topic.

\section{INTRODUCTION}

Sarcoidosis is a multisystem inflammatory granulomatous disease of unknown origin. Granulomas in sarcoidosis are compact, centrally organized collections of macrophages and epithelioid cells that are surrounded by lymphocytes. Granulomas from sarcoidosis are most often located in the lungs or its associated lymph nodes, but any organ can be affected.

Sarcoidosis affects approximately 10 out of 100,000 persons each year. ${ }^{1}$ Cardiac sarcoidosis is reported to involve only $2 \%-5 \%$ of patients with systemic sarcoidosis, ${ }^{2,3}$ even though autopsy studies indicate a considerably greater prevalence of $27 \% .^{4,5}$ There is also evidence indicating that sarcoidosis can be clinically confined to the heart. ${ }^{6}$ Cardiac involvement may range from silent myocardial granulomas to symptomatic conduction disturbances, ventricular arrhythmias, progressive heart failure, and sudden death, accounting for $13 \%-25 \%$ of disease-related deaths. ${ }^{5}$ The clinical course of cardiac sarcoidosis varies from benign to life-threatening with severe heart failure and sudden cardiac death. ${ }^{7}$ The management of cardiac sarcoidosis involves both immunosuppressive therapy for the treatment of sarcoidosis and cardiac-specific therapies to manage ventricular dysfunction and device therapy (pacemaker/ ICD) for heart blocks and heart rhythm disturbances. The decision for drug therapy alone or the implantation of an ICD for primary prevention in the early stage of cardiac sarcoidosis remains challenging. Nevertheless, it is felt that early initiation of immunosuppressive therapy may prevent progression of cardiac dysfunction and improve clinical outcomes. ${ }^{8}$

To date, the diagnosis and long-term management of cardiac involvement remain controversial. Cardiac sarcoid granulomas affect the whole heart but in a focal manner. Also, acutely inflamed epithelioid-cell granulomas as well as chronic fibrotic stage granulomas, may exist in different parts of the heart of any given patient. Consequently, blind endomyocardial biopsy of the right side of the interventricular septum has a low diagnostic yield, $20 \%-30 \%$, and it is unreliable to assess whole heart burden of inflammation or fibrosis. Molecular imaging of increased metabolic activity in the granulomas using ${ }^{18} \mathrm{~F}$-fluorodeoxyglucose (FDG) positron emission tomography (PET) provides the advantages of whole heart evaluation and the ability to identify granulomas with active inflammation. 
Cardiovascular magnetic resonance (CMR) on the other hand is highly sensitive to detect fibrosis. The Japanese Ministry of Health, Labour and Welfare (JMHW) criteria have been widely used for the diagnosis of cardiac sarcoidosis. But, they do not include FDG-PET or CMR. ${ }^{9}$ The Heart Rhythm Society (HRS) consensus document has included FDG-PET and CMR in the diagnostic criteria for cardiac sarcoidosis. ${ }^{10}$ However, procedural details of imaging are not covered in that document.

The purpose of this joint procedural position paper is to describe the role and the correct use of the different imaging techniques including radionuclide imaging [FDG-PET, radionuclide myocardial perfusion imaging (MPI)], CMR, and echocardiography for the management of patients with known or suspected cardiac sarcoidosis. We further hope that this position paper will aid in standardizing imaging for cardiac sarcoidosis with conventional and novel imaging techniques and facilitate clinical studies and pooling of multi-center data on cardiac sarcoidosis.

\section{ROLE OF DIFFERENT IMAGING TECHNIQUES IN CARDIAC SARCOIDOSIS}

\section{Echocardiography}

Rationale. Echocardiography is widely available and often provides the first suspicion for cardiac sarcoidosis.

Image acquisition. Several traditional and advanced echocardiographic approaches can be used with standard acquisition and interpretation protocols. ${ }^{11-18}$ Stress echocardiography has a limited role in the diagnosis of cardiac sarcoidosis; it may be helpful to exclude epicardial coronary artery disease as a cause of left ventricular systolic dysfunction and focal regional wall motion abnormalities.

Interpretation and reporting. Cardiac sarcoidosis can manifest with normal function or with dilated or restrictive cardiomyopathy. ${ }^{19-21}$ The ventricle may be globally hypokinetic or the patchy nature of sarcoid infiltration of the heart may result in regional wall motion abnormalities in a non-coronary distribution. Mild wall thickening may be present related to oedema or infiltration. In some cases, the increase in myocardial wall thickness (>13 mm) can simulate LV hypertrophy. Increased ventricular wall echogenicity (bright aspect), particularly the ventricular septum or the LV free wall, is frequent; and can reflect scar formation and granulomatous inflammation. More commonly, areas of wall thinning are seen, especially in the ventricular septum, probably as a result of scar. A typical but uncommon finding is the thinning $(<7 \mathrm{~mm})$ and akinesia of the basal septum, while the distal septum and apex are contracting normally, and the presence of ventricular aneurysm in the inferolateral wall ${ }^{20,22-24}$ (Figure 1). Echocardiographic features of cardiac sarcoidosis echo can also mimic arrhythmogenic right ventricular dysplasia/cardiomyopathy. ${ }^{25,26}$ In the early stage of the disease, reduced longitudinal myocardial function (2D speckle tracking or tissue Doppler imagingderived strain $)^{27-32}$ or alterations in acoustic properties of the myocardium, ${ }^{33,34}$ particularly in the basal interventricular septum, may be present in the absence of other 2D echo features. About $20 \%$ of patients with cardiac sarcoidosis have atrial lesions characterized by atrial wall hypertrophy (easier diagnosis by transoesophageal echocardiography). ${ }^{35}$ On rare occasions, an appearance similar to hypertrophic cardiomyopathy can be observed. ${ }^{36,37}$ Any degree of diastolic dysfunction is a common but nonspecific finding. ${ }^{38}$ Small pericardial effusions, mitral, or tricuspid regurgitation secondary to papillary muscle dysfunction, pulmonary hypertension secondary to lung implication, and/or ventricular dys-synchrony are other echo parameters that can be potentially observed in cardiac sarcoidosis. Tamponade and constrictive pericarditis have been infrequently found. ${ }^{19}$ The right ventricular dilatation and dysfunction at the end stage disease in cardiac sarcoidosis as well as the predominance of basal septum abnormalities in terms of contractility are important findings on echocardiography. ${ }^{25}$

Diagnostic accuracy. Echocardiography can detect cardiac structural abnormalities from cardiac sarcoidosis. But in patients with extracardiac sarcoidosis, echocardiographic abnormalities are highly variable, ranging from $4 \%$ to $55 \%$, even without clinical symptoms or ECG abnormalities. ${ }^{3,10}$ The measurement of LV systolic and diastolic function and evaluation of valvular disease severity are not specific for sarcoidosis. ${ }^{39}$ Although newer techniques such as Doppler, strain, and speckle tracking echocardiography are useful in detecting abnormal myocardial function, these imaging techniques cannot delineate tissue characteristics and therefore cannot differentiate between various types of cardiomyopathies. ${ }^{40}$ Using the criteria of RV systolic dysfunction in the absence of pulmonary hypertension, and/or significant diastolic dysfunction inappropriate for the patient's age, echocardiography yields a sensitivity of $10 \%-47 \%$ and a specificity of $82 \%-99 \%$ for the diagnosis of cardiac sarcoidosis. ${ }^{10,41}$

In summary, standard 2D transthoracic echocardiography is a common initial test in patients with suspected cardiac sarcoidosis. However, findings are frequently non-specific for inflammation and not sensitive for early changes from sarcoidosis. The primary role of echocardiography in cardiac sarcoidosis, at this time, is to assess and follow LV function. 


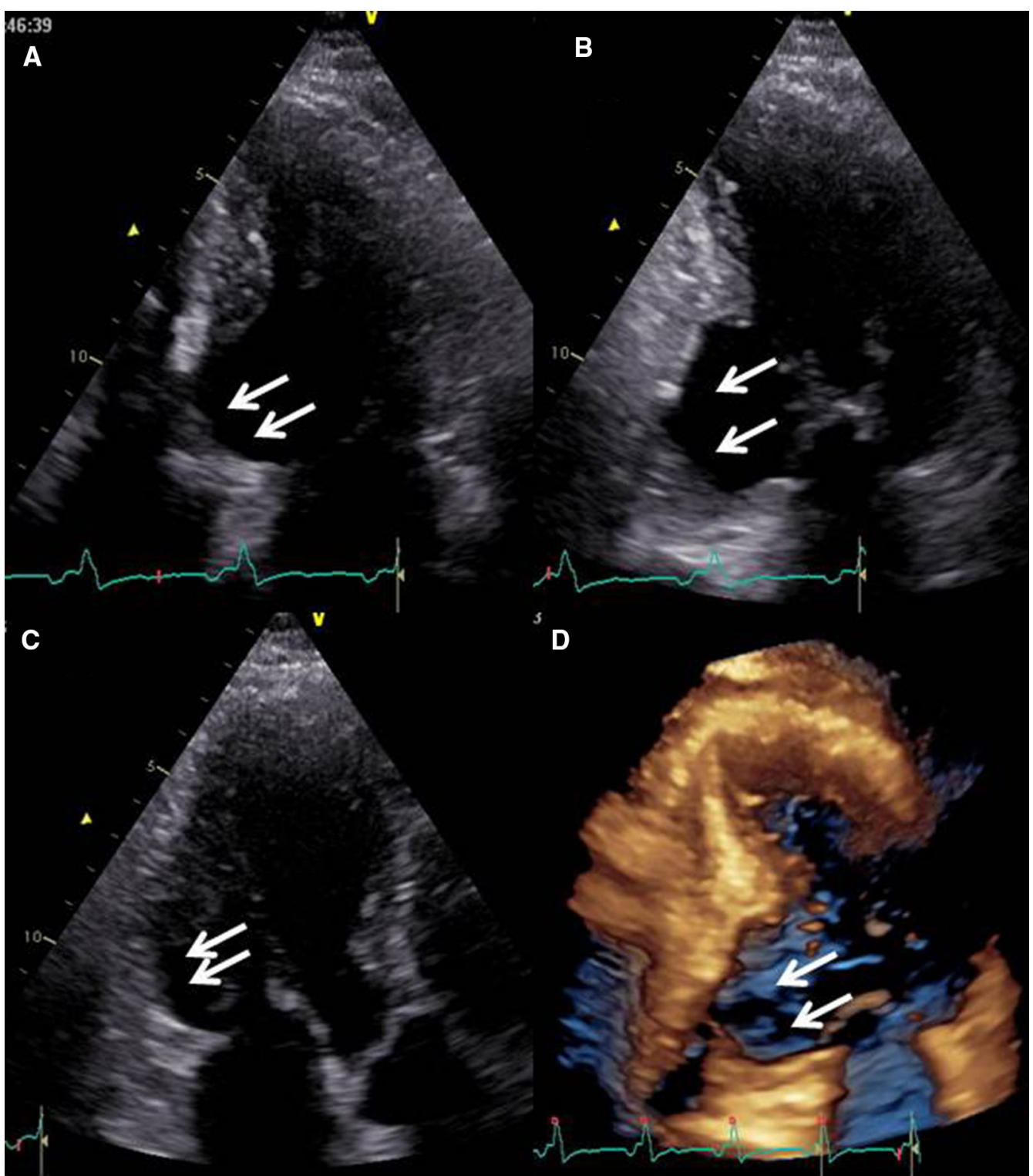

Figure 1. Example of echocardiography in cardiac sarcoidosis. Echocardiographic images showing (A) a basal thinned basal septal wall (four-chamber view showing, arrows), (B-D) aneurysmal dilatation involving inferior $(\mathbf{B}, \mathbf{D})$, and posterolateral $(\mathbf{C})$ walls. (D) 3D image displaying the inferior aneurysm (arrows).

\section{RADIONUCLIDE IMAGING}

Radionuclide imaging with ${ }^{67}$ gallium-citrate SPECT and FDG-PET have been used to diagnose myocardial inflammation. ${ }^{67}$ Gallium-citrate is specific for inflammation, but has relatively low sensitivity and poor spatial resolution compared with FDG-PET, especially for detecting extra-pulmonary sarcoidosis involvement. ${ }^{42}$ Therefore, the use of ${ }^{67}$ gallium-citrate SPECT to diagnose cardiac sarcoidosis is limited to centers without access to FDG-PET. FDG-PET has emerged as a powerful and most commonly used technique not only to assess the extent of systemic sarcoidosis but also to assess extent and activity of myocardial involvement. ${ }^{43}$ In addition, recent studies have demonstrated the importance of identifying perfusion defects in patients with cardiac sarcoidosis, as this group of patients is at highest risk for death or ventricular arrhythmias. ${ }^{44,45}$ FDG-PET in conjunction with MPI is therefore the currently recommended radionuclide method for evaluation of cardiac sarcoidosis. 


\section{${ }^{18}$ F-Fluorodeoxyglucose Positron Emission Tomography}

Rationale. Active inflammatory cells have high glycolytic activity to sustain their energy demands; the accumulation of FDG in these activated macrophages and $\mathrm{CD} 4^{+} \mathrm{T}$ lymphocytes is the underlying mechanism for in vivo visualization of active granulomatous sarcoid lesions in various organs. ${ }^{46}$ Low carbohydrate diet and prolonged fasting of the subject are recommend to suppress myocardial FDG uptake to facilitate visualizing FDG uptake in these inflammatory cells of cardiac sarcoidosis. The role of FDG-PET for the diagnosis of extracardiac sarcoidosis is well established; in contrast, its role in cardiac sarcoidosis management and therapy is currently under active investigation.

Patient preparation and image acquisition. Metabolic imaging to identify the non-caseating granulomas of cardiac sarcoidosis takes advantage of enhanced FDG uptake based on the high glycolytic activity of inflammatory cells. ${ }^{47,48}$ However, the surrounding normal myocardium can also use glucose as an energy substrate, and therefore, it is important to minimize physiological myocardial glucose utilization to optimize the target to background ratio of FDG-PET for identifying active cardiac sarcoid lesions. Patient preparation for cardiac FDG-PET imaging for sarcoidosis is based on increasing the provision of fatty acids to the heart and decreasing physiological uptake of glucose by the myocardium. ${ }^{103}$ The current SNMMI/American Society of Nuclear Cardiology (ASNC)/SCCT guidelines recommend preparation with a fat-enriched diet lacking carbohydrates for 12-24 hours prior to the scan, a 12-18 hours fast, and/or the use of intravenous unfractionated heparin approximately 15 minutes prior to ${ }^{18} \mathrm{~F}$-FDG injection. ${ }^{49}$ Careful patient preparation is critical to optimize FDG-PET image quality. Details of patient preparation are listed in Supplementary data online, Supplement $1 \mathrm{l}$ and $1 \mathrm{~b}$.

The FDG-PET imaging protocol involves cardiac image acquisition 90 minutes (minimum of 60 minutes) after intravenous injection of $2.5-5 \mathrm{MBq} \cdot \mathrm{kg}^{-1}$ of FDG $^{50-52}$ (Table 1). Following FDG injection and before the images are obtained, the patient should continue to fast and should not be physically active, as either of these will enhance myocardial glucose uptake. In addition, limited whole body FDG imaging is recommended to allow for the assessment of extracardiac disease activity (lung, lymph nodes, liver, spleen, kidneys, and bones) and identify potential sites amenable for biopsy. Imaging procedures, including dietary preparation and image acquisition parameters should be documented and standardized on repeat studies, to enable reliable quantitation and comparison of changes.
Exercise and/or myocardial ischemia can enhance myocardial FDG uptake. For this reason, stress testing should be avoided and patients should be advised not to exert themselves on the day of cardiac sarcoid FDG imaging. Also, note that patients with systolic LV dysfunction may have increased glucose uptake due to metabolic changes, which is likely diffuse rather than focal.

Interpretation and reporting. Interpretation of FDG-PET for cardiac sarcoidosis requires an understanding of the metabolic preparations necessary to differentiate the pathological glucose uptake that is the hallmark of sarcoidosis-related inflammation from physiological myocardial glucose uptake. It is also important to note that none of the interpretive strategies described below have been validated experimentally, due to the lack of a gold standard, and there is little data available on comparing the various methods. The most common method of interpreting FDG-PET for the evaluation of cardiac sarcoidosis relies on the use of traditional nuclear cardiology display systems as well as nuclear medicine display systems. ${ }^{53}$ Typically short-axis, horizontal, and vertical long-axis images of the FDG and rest MPI are displayed together with the image intensity normalized to the maximum counts per pixel of the respective data set. These normalized images are reviewed for four imaging patterns ${ }^{54}$ :

1. No FDG uptake ('none'),

2. Diffuse FDG uptake ('diffuse'),

3. Focal FDG uptake ('focal'),

4. Focal on diffuse FDG uptake ('focal on diffuse').

The presence of 'focal' or 'focal on diffuse' FDG uptake is abnormal and may be consistent with cardiac inflammation from sarcoidosis, while interpretation of diffuse uptake is challenging as it can be non-specific (possibly related to poor suppression of normal myocardial glucose uptake) or may represent multiple sarcoid granulomas with heterogeneous FDG uptake in a diffuse distribution. The normal FDG image pattern for an appropriately prepared patient is no myocardial FDG uptake where the LV blood pool is brighter than the myocardium, although low intensity FDG uptake in the lateral wall is also often considered a normal finding, particularly when such uptake is homogenous in intensity and is not associated with any resting perfusion defects. ${ }^{54}$ In addition to evaluating for abnormal FDG uptake in the LV, it is also important to evaluate for areas of focal FDG uptake in the right ventricle, which may be associated with a worse prognosis. ${ }^{45}$ Lastly, the use of FDG-PET combined with MPI will be particularly helpful to judge the orientation of the image when only focal FDG uptake is present. 
Table 1. Procedure guidelines for radionuclide myocardial perfusion and FDG imaging for cardiac sarcoidosis

\section{Myocardial perfusion imaging and FDG-PET at baseline Imaging sequence Myocardial perfusion imaging and FDG-PET at follow-u \\ Standard}

\author{
Myocardial perfusion \\ imaging \\ Preparation \\ Technique \\ Perfusion radiotracers \\ Protocols
}

Review
FDG-PET imaging
Preparation
Type of PET scan
CT scan
Imaging mode
Dose
FDG uptake period after
injection
Scan field of view

Scan duration

Scan type

Scan reconstruction

Scan interpretation

Special considerations
None

Preparation for FDG-PET, if performed on the same day

PET or SPECT

${ }^{99 m}$ Tc-sestamibi/tetrofosmin, ${ }^{201} \mathrm{Tl},{ }^{13} \mathrm{~N}$-ammonia, ${ }^{82} \mathrm{Rb}$

Standard radiotracer dose and rest MPI protocols as per ASNC, EANM, ESC

Attenuation correction when available

Gated SPECT/PET MPI

Review MPI along with FDG-PET

Dietary preparation to minimize physiological myocardial glucose utilization

Hybrid PET/CT

Dedicated PET

Low dose chest CT scan for attenuation correction without iodinated contrast

3D

2D

2.5-5 $\mathrm{MBq} \cdot \mathrm{kg}^{-1}$ for 3D mode or

5-10 $\mathrm{mCi}$ for 3D imaging and $10-20 \mathrm{mCi}$ for 2D imaging

90 minute

60 minute

Standard

Standard

Standard

Standard

Standard

Standard

Dedicated cardiac scan and whole body to include neck through pelvis at Standard baseline

Dedicated cardiac scan and whole body to include neck through pelvis at Standard follow-up

10 minute for 3D cardiac PET

Standard

20 minute for 2D cardiac PET

Standard

3 minute per bed position partial whole body PET

Standard

Static FDG-PET

Standard

Gated FDG-PET

Iterative reconstruction (OSEM)

Optional

Attenuation correction

Standard

With and without attenuation correction for hybrid PET/CT in individuals with intracardiac devices

Visual using cardiac imaging planes

Standard

Standard

Standard

Whole body imaging using SUV scale

Standard

Myocardial SuV $\max$

Standard

Volume of myocardium above specific SUV threshold

Standard

Interpretation by physicians experienced in nuclear cardiology, CT and

Standard

FDG imaging

In individuals with recent intracardiac device placement or ablation wait 4- Optional 6 weeks for FDG-PET 
The use of traditional nuclear cardiology display systems to interpret relative FDG-PET images for cardiac sarcoidosis has two limitations. First, since these display schemes normalize image intensity to the most intense pixel, it is difficult to judge the absolute intensity of myocardial FDG uptake. This may be important for understanding the severity of myocardial inflammation and for evaluating the response to treatment, particularly if only the intensity but not the distribution of FDG uptake changes between studies. Secondly, the issue of normalization is especially important when the FDG signal is only mildly increased above background. This can falsely cause these areas of low absolute uptake to appear artificially intense in the normalized display.

A review of the images for non-inflammatory pathological FDG activity (cancer, other infections, etc.) is accomplished using limited whole body hybrid PET/CT. Hybrid FDG-PET/CT imaging, however, may be problematic in individuals with intracardiac devices due to apparent focal increase in FDG uptake at the site of lead insertion related to errors from CT-based attenuation correction and/or focal inflammation. In individuals with intracardiac devices and suspected cardiac sarcoidosis, the nonattenuation corrected FDG images could be reviewed to overcome this limitation.

In addition to a visual review of the relative scaled FDG images and hybrid PET-CT images, FDG images should be assessed using a semi-quantitative scale and standardized uptake values (SUVs). SUVs are defined as the radioactivity concentration in the region of interest in $\mathrm{Bq} \cdot \mathrm{mL}^{-1} /$ (injected dose in Bq.patient weight in $\left.\mathrm{g}^{-1}\right) .{ }^{55}$ Various metrics for quantification of FDG uptake in cardiac sarcoidosis have been reported, including the maximal SUV values in the heart $\left(\mathrm{SUV}_{\max }\right),{ }^{45,55}$ the total SUV value of the heart, ${ }^{55}$ mean SUV of the heart, ${ }^{56}$ heart-to-blood pool SUV ratios, ${ }^{57}$ coefficient of variance of SUVs, ${ }^{58}$ and the volume, ${ }^{59}$ and volume-activity ${ }^{44,59}$ of voxels with intensities of FDG SUVs above various thresholds. While these methods have not been rigorously compared head-to-head, there is data to suggest that they perform better than visual assessment of normalized images to assess treatment response. ${ }^{44,59,60}$ A standard FDG-PET for cardiac sarcoidosis is typically reported in conjunction with rest MPI (see Supplementary data online, Supplement 2).

Myocardial perfusion imaging. Cardiac sarcoidosis may alter coronary microcirculation leading to myocardial perfusion defects. Myocardial perfusion abnormalities, including reversible perfusion defects with adenosine or dipyridamole, have been reported in cardiac sarcoidosis. ${ }^{56,61,62}$ However, unlike with coronary artery disease, perfusion abnormalities related to sarcoid granulomas typically do not match with coronary territories. In the chronic phase, when epithelioidcell granulomas have been replaced by fibrosis, perfusion defects become irreversible and may be associated with segmental motion abnormalities according to the transmural extent of the fibrotic scar.

The evaluation of the diagnostic performance of perfusion SPECT and perfusion PET in cardiac sarcoidosis is very scarce and limited. ${ }^{54-56}$ The potential additional value of myocardial blood flow quantification by PET in the diagnosis and evaluation of cardiac sarcoidosis remains to be investigated. Due to the limited sensitivity and specificity of MPI alone, and due to the fact that abnormal MPI alone cannot distinguish scar from active sarcoidosis, MPI is currently used for the evaluation of cardiac sarcoidosis only in conjunction with FDG-PET.

When combined with FDG-PET, standard PET or SPECT MPI protocols are recommended. ${ }^{63-66}$ PET MPI has advantages over SPECT for the identification of small perfusion defects, as seen in patients with cardiac sarcoidosis. When SPECT imaging is used, attenuation correction and gated imaging are recommended to avoid interpreting segments with attenuation artifacts as segments of true mismatch. ${ }^{67}$ Perfusion and FDG abnormalities associated with cardiac sarcoidosis are not specific for inflammation or scar from sarcoidosis. Consequently, it is mandatory to rule out alternative diagnoses such as CAD before interpreting myocardial perfusion images.

Combined assessment of perfusion and inflammation. The combined assessment of perfusion and inflammation, preferably in hybrid imaging setting, is likely to provide additional information about the status of cardiac sarcoidosis (scar or inflammation) and risk from cardiac involvement (Figure 2). In this section, we will only consider the assessment of inflammation by FDG-PET/CT combined with MPI since ${ }^{67}$ gallium-citrate scintigraphy is no longer regarded as a method of choice.

Perfusion defects in patients with cardiac sarcoidosis can represent areas of scar or inflammation, while abnormal FDG uptake represents inflammation (Table 2). FDG and MPI patterns have been described as 'early' (only FDG-positive), 'progressive inflammatory' (FDG-positive without major perfusion defects), 'peak active' (high SUV FDG uptake with small perfusion defects), 'progressive myocardial impairment' (high SUV FDG uptake with large perfusion defects) or 'fibrosis-predominant' (FDG negative, but with perfusion defects) ${ }^{55}$ (Figure 2B). Another staging system utilizes a nomenclature analogous to the scadding system for staging pulmonary sarcoidosis, specifically, Stage 0 (normal FDG, normal perfusion), Stage 1 (FDG- 

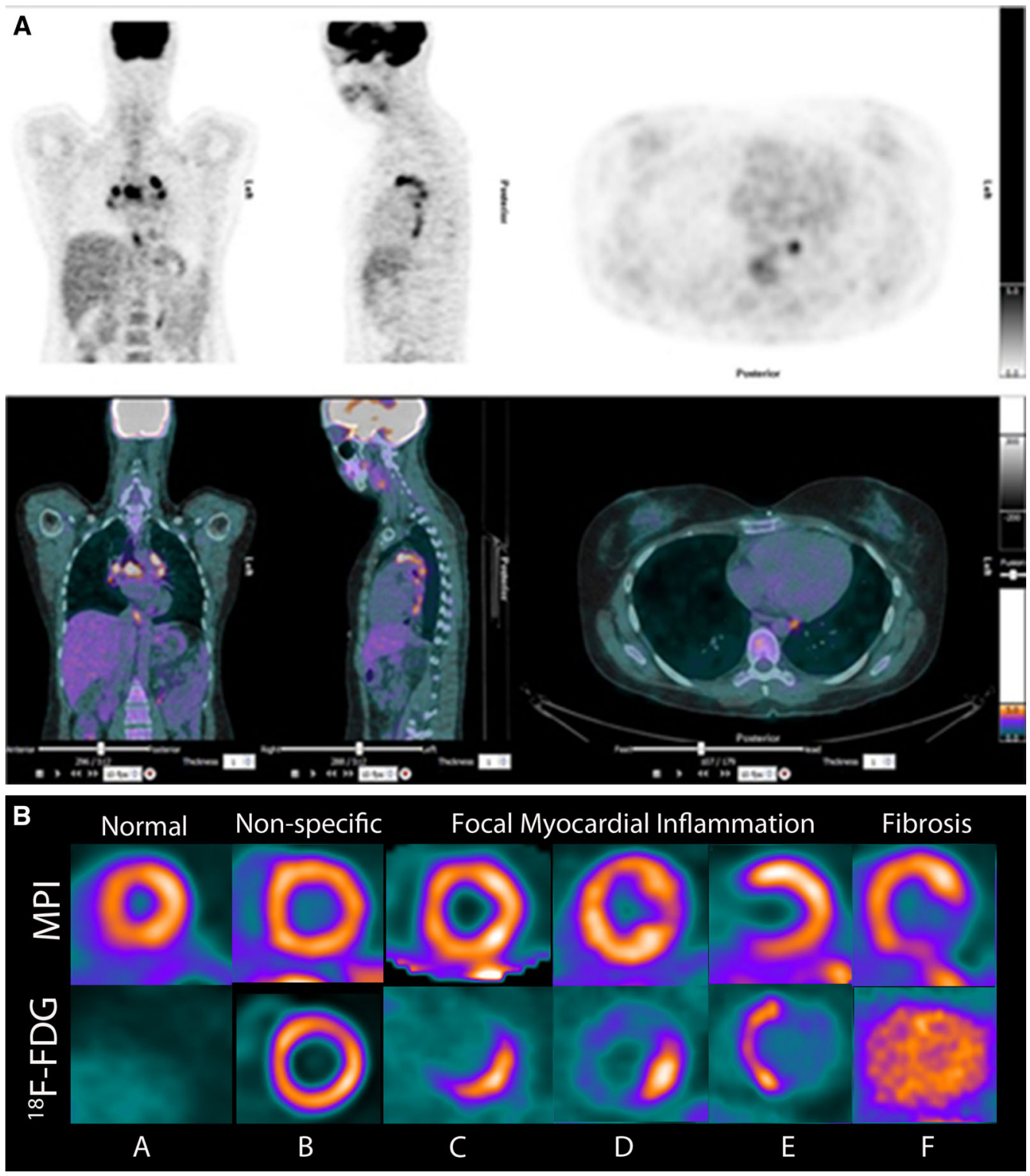

Figure 2. (A) Example of FDG and myocardial perfusion PET in sarcoidosis. The whole body hybrid FDG-PET/CT study (A) showed multiple foci of inflammation in the mediastinum, but no active inflammation in the myocardium; hybrid imaging confirms regions of FDG uptake in the mediastinal lymph nodes and not the myocardium. Assessment of systemic disease activity is an advantage of FDG-PET compared with echocardiography or CMR. (B) Patterns of myocardial perfusion imaging (MPI) and FDG imaging of myocardial inflammation. This figure shows rest MPI in the top row and FDG imaging of myocardial inflammation in the bottom row. A pattern of no myocardial FDG uptake is normal if MPI is normal $(A)$, or fibrosis when MPI is abnormal $(F$, the pattern of FDG uptake represents blood pool activity). A pattern of diffuse myocardial FDG uptake represents a non-specific finding that may be seen with incomplete suppression of physiological myocardial glucose utilization and is not diagnostic for cardiac sarcoidosis $(B)$. A pattern of focal myocardial FDG uptake is consistent with active myocardial inflammation without $(C, D$, no perfusion defect) or with coexistent fibrosis ( $E$, perfusion defect). Of note, pattern $(C)$, isolated focal FDG uptake in the basal lateral wall in the absence of a perfusion defect, abnormal wall motion, or delayed enhancement on CMR may have reduced specificity for active myocardial inflammation. 
Table 2. Interpretation of combined rest perfusion and FDG imaging

\begin{tabular}{|c|c|c|}
\hline $\begin{array}{c}\text { Rest } \\
\text { perfusion }\end{array}$ & FDG & Interpretation \\
\hline \multicolumn{3}{|c|}{ Normal perfusion and metabolism } \\
\hline Normal & No uptake & Negative for cardiac sarcoidosis \\
\hline Normal & Diffuse & $\begin{array}{l}\text { Diffuse (usually homogeneous) FDG most likely } \\
\text { due to suboptimal patient preparation }\end{array}$ \\
\hline Normal & Isolated lateral wall uptake & May be a normal variant \\
\hline \multicolumn{3}{|c|}{ Abnormal perfusion or metabolism } \\
\hline Normal & Focal & Could represent early disease \\
\hline Defect & No uptake & $\begin{array}{l}\text { Perfusion defect represents scar from sarcoidosis } \\
\text { or other etiology }\end{array}$ \\
\hline \multicolumn{3}{|c|}{ Abnormal perfusion and metabolism } \\
\hline Defect & Focal in area of perfusion defect & Active inflammation with scar in the same location \\
\hline Defect & $\begin{array}{l}\text { Focal on diffuse with focal in area of } \\
\text { perfusion defect }\end{array}$ & $\begin{array}{l}\text { Active inflammation with scar in the same location } \\
\text { with either diffuse inflammation or suboptimal } \\
\text { preparation }\end{array}$ \\
\hline Defect & Focal in area of normal perfusion & $\begin{array}{l}\text { Presence of both scar and inflammation in different } \\
\text { segments of the myocardium }\end{array}$ \\
\hline
\end{tabular}

Adapted from Blankstein et $\mathrm{al}^{45}$

positive, normal perfusion), Stage 2 (FDG-positive with perfusion defects in the same myocardial segments), Stage 3 (FDG-positive with perfusion defects in different segments), or Stage 4 (normal FDG, but perfusion defects). ${ }^{68}$

Notably, the pattern of perfusion and inflammation abnormalities in relation to the disease status is not validated histologically or by outcomes. However, this relationship may be important both for diagnosis, and for the determination of prognosis and establishing treatment, ${ }^{44,45,55}$ see next sections. It is noteworthy that both resting perfusion defects as well as increased FDG uptake may be caused by inflammation as well as associated microvascular compression and local ischemia; for this reason, some perfusion defects may actually improve following immunosuppressive therapy.

Diagnostic accuracy. FDG-PET is an accurate tool for the detection of cardiac involvement in sarcoidosis. Several studies reported on the sensitivity and specificity of FDG-PET to detect cardiac sarcoidosis. ${ }^{1}$ These studies have included patients with and without endomyocardial biopsy-proven cardiac involvement. However, as with the data from the other imaging methods, most of these studies were observational in nature, included small sample size, lacked an adequate reference standard, were limited by referral bias, and used different protocols.

The sensitivity of FDG-PET for detecting cardiac sarcoid is $85 \%-100 \%$ for most studies while the specificity is more variable $(39 \%-100 \%)$ using the JMHW criteria as the gold standard (Table 3). ${ }^{53-55,57,69,70} \mathrm{~A}$ recent meta-analysis of seven studies demonstrated an overall sensitivity of $89 \%$ and a specificity of $78 \%$ for FDG-PET. ${ }^{70}$ However, these estimates are biased as the lower specificity of PET in some studies may reflect the fact that this test is more sensitive for identifying cardiac sarcoidosis than the JMHW criteria. Indeed, the requirement of histologically proven extracardiac sarcoidosis by the JMHW criteria limits identification of isolated cardiac sarcoidosis, whereby the disease is confined only to the heart, ${ }^{71}$ particularly if endomyocardial biopsy is negative. Likewise, the lower sensitivity of FDG-PET in some studies may reflect the reduced specificity of the JMHW criteria. Several studies have compared FDGPET, either alone or combined with PET MPI, to ${ }^{67}$ gallium imaging and have demonstrated improved accuracy for detecting cardiac sarcoid. ${ }^{42,53,54,57,72}$ Despite the high diagnostic accuracy of FDG-PET, it is currently not included in the most recent updated (2006) diagnostic criteria of the JMHW, published by the Japan Society of Sarcoidosis and Other Granulomatous Disorders. ${ }^{9}$ The more recent HRS Consensus Recommendations ${ }^{10}$ suggest that clinical diagnosis of cardiac sarcoidosis is probable if there is histological proof of extracardiac sarcoidosis and one or more findings which include a pattern consistent with cardiac sarcoidosis on imaging [including dedicated cardiac PET, late gadolinium enhancement (LGE) on CMR, positive ${ }^{67}$ gallium imaging], unexplained reduced left ventricular ejection fraction (LVEF) $<40 \%$, unexplained 
Table 3. Sensitivity and specificity of FDG-PET for detecting cardiac sarcoidosis

\begin{tabular}{|c|c|c|c|c|c|c|}
\hline References & Years & Patients & EMB & Sensitivity & Specificity & Remarks \\
\hline Yamagishi et al ${ }^{53}$ & 2003 & 17 & $0 / 17$ & 100 & n.a. & $\begin{array}{l}\text { Only patients with histologic } \\
\text { evidence of extracardiac } \\
\text { sarcoidosis were included }\end{array}$ \\
\hline Okumura et al ${ }^{55}$ & 2004 & 22 & $3 / 22$ & 100 & 90.9 & Diagnosis JMHW \\
\hline Ishimaru et $\mathrm{al}^{54}$ & 2005 & 62 & $0 / 62$ & 100 & 81.5 & $\begin{array}{l}\text { Included } 30 \text { healthy controls and } \\
32 \text { patients with suspected } \\
\text { sarcoidosis. Diagnosis } 28 \text { out of } \\
32 \text { with histologic evidence of } \\
\text { extracardiac sarcoidosis }\end{array}$ \\
\hline Nishiyama et al ${ }^{42}$ & 2006 & 18 & $0 / 18$ & 100 & 100 & Diagnosis JMHW \\
\hline Ohira et al ${ }^{69}$ & 2008 & 21 & $2 / 21$ & 87.5 & 38.5 & Diagnosis JMHW \\
\hline Langah et $\mathrm{l}^{57}$ & 2009 & 65 & $1 / 65$ & 85 & 90 & Diagnosis JMHW \\
\hline Youssef et al ${ }^{70}$ & 2012 & 164 & n.a. & 89 & 78 & $\begin{array}{l}\text { Meta-analysis of seven studies } \\
\text { Diagnosis JMHW }\end{array}$ \\
\hline 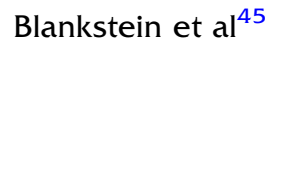 & 2014 & 118 & $13 / 118$ & 42.1 & 79.7 & $\begin{array}{l}\text { Based on patients that had both } \\
\text { abnormal FDG and }{ }^{82} \text { rubidium } \\
\text { PET studies } \\
\text { Diagnosis JMHW }\end{array}$ \\
\hline
\end{tabular}

$E M B$, endomyocardial biopsy

sustained [spontaneous or induced ventricular tachycardia (VT)], second degree atrio-ventricular (AV) heart block (Type 2, also called Mobitz Type II) or third degree heart block, steroid/immunosuppression responsive cardiomyopathy or heart block, and other causes for the cardiac manifestation(s) have been reasonably excluded.

In summary, FDG-PET is the best clinically available tool for imaging myocardial inflammation. Careful preparation to suppress physiological myocardial glucose utilization is essential for FDG-PET imaging of cardiac sarcoidosis. Combined assessment of perfusion and inflammation is necessary to provide optimal information for the diagnosis, risk assessment, and management of cardiac sarcoidosis.

\section{CARDIOVASCULAR MAGNETIC RESONANCE}

\section{Rationale}

CMR can provide a wide range of potentially unique information in inflammatory and infiltrative heart disease. Specific CMR imaging sequences with characteristic findings in cardiac sarcoidosis have been reported. Although evidence from large-scale prospective clinical studies for the use of CMR in cardiac sarcoidosis is lacking, several smaller studies have demonstrated its potential to detect cardiac involvement in sarcoidosis and predict adverse clinical outcome.

\section{Image Acquisition}

Patient preparation for CMR is detailed in Supplementary data online, Supplement 3. Standardized acquisition protocols are available for all modern cardiac enabled MRI scanners ${ }^{73}$ and in suspected cardiac sarcoidosis typically include low resolution localizer images, cine imaging in multiple planes, oedema sensitive (T2-weighted), and LGE imaging, with parametric mapping as an emerging addition. Images should be acquired with standardized methods ${ }^{73}$ and in standardized and reproducible imaging planes, allowing reliable correlation between different components of the study. T2 weighted images, most commonly using short tau inversion-recovery (T2-STIR) methods, are sensitive to the free water content of tissue and can thus detect myocardial inflammation and oedema in cardiac sarcoidosis $^{74}$ (Table 4). T2-STIR methods suffer from relatively low sensitivity, however, due to low contrast to noise ratio and can also be affected by artifacts from slow moving blood at the endocardial surface. LGE imaging uses dual inversion saturation recovery pulse sequences to delineate myocardial tissue with expanded extracellular space as occurs in infiltration, scaring, or fibrosis. Granulomatous infiltration in cardiac sarcoidosis can be sensitively detected with this method as focal hyperenhancement. ${ }^{7,76-81}$ Cine CMR is most commonly performed with steady state free precession (SSFP) methods, acquiring a stack of images 
Table 4. Recommended CMR protocol and analysis in sarcoidosis

\begin{tabular}{|c|c|c|c|}
\hline & Pulse sequence & Imaging planes & Analysis and tips \\
\hline \multirow[t]{4}{*}{$\begin{array}{l}\text { Morphology and } \\
\text { function }\end{array}$} & $\begin{array}{l}\text { (1) Steady state free } \\
\text { precession (SSFP) cine } \\
\text { imaging }\end{array}$ & $\begin{array}{l}\text { (i) Whole heart } \\
\text { coverage in LV } \\
\text { short-axis plane } \\
\text { from the mitral valve } \\
\text { to the apex }\end{array}$ & $\begin{array}{l}\text { Use real time acquisition } \\
\text { in patients with poor } \\
\text { breath holding }\end{array}$ \\
\hline & $\begin{array}{l}\text { Slice thickness } 6-8 \mathrm{~mm} \text {, with } \\
2-4 \mathrm{~mm} \text { interslice gaps to } \\
\text { equal } 10 \mathrm{~mm}\end{array}$ & $\begin{array}{l}\text { (ii) Four-chamber } \\
\text { plane }\end{array}$ & \multirow{3}{*}{$\begin{array}{l}\text { Report regional and } \\
\text { global LV and RV } \\
\text { function as well as } \\
\text { aneurysms and other } \\
\text { morphological } \\
\text { abnormalities }\end{array}$} \\
\hline & $\begin{array}{l}\text { Temporal resolution } \leq 45 \mathrm{~ms} \\
\text { between phases }\end{array}$ & $\begin{array}{l}\text { (iii) Vertical long-axis } \\
\text { plane }\end{array}$ & \\
\hline & Parallel imaging as available & $\begin{array}{l}\text { (iv) LV outflow tract } \\
\text { (LVOT) plane }\end{array}$ & \\
\hline \multirow[t]{5}{*}{ T2-weighted imaging } & $\begin{array}{l}\text { (1) Black blood T2-weighted } \\
\text { STIR (short tau inversion } \\
\text { recovery) }\end{array}$ & $\begin{array}{l}\text { Same planes as for } \\
\text { cine imaging (short- } \\
\text { and long-axis views) }\end{array}$ & $\begin{array}{l}\text { Report presence of focal } \\
\text { signal enhancement } \\
\text { suggestive of oedema }\end{array}$ \\
\hline & $\begin{array}{l}\text { (2) Bright blood T2-weighted } \\
\text { sequences }\end{array}$ & & \multirow{4}{*}{$\begin{array}{l}\text { Beware slow flow } \\
\text { artifacts at endocardial } \\
\text { border in particular in } \\
\text { long-axis planes }\end{array}$} \\
\hline & $\begin{array}{l}\text { (a) T2-prepared single-shot } \\
\text { SSFP sequence }\end{array}$ & & \\
\hline & (b) Turbo spin echo-steady & & \\
\hline & SSFP hybrid & & \\
\hline \multirow[t]{11}{*}{$\begin{array}{l}\text { Late gadolinium } \\
\text { enhancement }\end{array}$} & $\begin{array}{l}\text { (1) } 2 \mathrm{D} / 3 \mathrm{D} \text { segmented } \\
\text { inversion-recovery gradient } \\
\text { or SSFP pulse sequence }\end{array}$ & \multirow[t]{11}{*}{$\begin{array}{l}\text { Same planes as for } \\
\text { cine imaging (short- } \\
\text { and long-axis views) }\end{array}$} & $\begin{array}{l}\text { PSIR is less dependent on } \\
\text { correct TI }\end{array}$ \\
\hline & $\begin{array}{l}\text { (2) Phase-sensitive inversion- } \\
\text { recovery (PSIR) pulse } \\
\text { sequence } \\
\text { (3) Single-shot imaging (SSFP } \\
\text { readout) }\end{array}$ & & $\begin{array}{l}\text { Use single shot for } \\
\text { patients with irregular } \\
\text { heart rhythm, and/or } \\
\text { difficulty breath } \\
\text { holding }\end{array}$ \\
\hline & $\begin{array}{l}\text { Slice thickness same as for } \\
\text { cine imaging }\end{array}$ & & $\begin{array}{l}\text { Report presence of focal } \\
\text { hyperenhancement }\end{array}$ \\
\hline & $\begin{array}{l}\text { In-plane resolution, } \sim 1.4- \\
1.8 \mathrm{~mm}\end{array}$ & & \multirow[t]{8}{*}{$\begin{array}{l}\text { Consider using } \\
\text { thresholding methods }\end{array}$} \\
\hline & $\begin{array}{l}\text { Inversion time to null normal } \\
\text { myocardium }\end{array}$ & & \\
\hline & Acquisition duration per R-R & & \\
\hline & interval below 200 ms, less & & \\
\hline & in the setting of tachycardia & & \\
\hline & $\begin{array}{l}\text { Readout usually every other } \\
\text { heart beat unless tachycardia } \\
\text { or bradycardia }\end{array}$ & & \\
\hline & $\begin{array}{l}\text { Images acquired during } \\
\text { diastolic stand-still }\end{array}$ & & \\
\hline & $\begin{array}{l}\text { Acquired at least } 10 \text { minute } \\
\text { after gadolinium injection }\end{array}$ & & \\
\hline
\end{tabular}


Table 4 continued

\begin{tabular}{|c|c|c|c|}
\hline & Pulse sequence & Imaging planes & Analysis and tips \\
\hline T2 mapping (optional) & $\begin{array}{l}\text { (1) T2-prepared single-shot } \\
\text { SSFP sequence acquired with } \\
\text { different T2 prep time }\end{array}$ & Typically LV short-axis & $\begin{array}{l}\text { Acquire prior to contrast } \\
\text { administration } \\
\text { Review maps for } \\
\text { presence of focal signal } \\
\text { enhancement } \\
\text { suggestive of oedema }\end{array}$ \\
\hline T1 mapping (optional) & $\begin{array}{l}\text { (1) Look locker imaging } \\
\text { (MOLLI or ShMOLLI or } \\
\text { equivalent) } \\
\text { (2) Saturation recovery single- } \\
\text { shot acquisition (SASHA) }\end{array}$ & Typically LV short-axis & $\begin{array}{l}\text { Performed prior to } \\
\text { contrast and at 2-4 } \\
\text { time points post- } \\
\text { contrast bolus } \\
\text { Alternatively, constant } \\
\text { infusion of contrast can } \\
\text { be used rather than } \\
\text { bolus } \\
\text { Review maps for } \\
\text { presence of focal signal } \\
\text { enhancement } \\
\text { suggestive of } \\
\text { oedema/fibrosis }\end{array}$ \\
\hline
\end{tabular}

Modified from Kramer et al $^{75}$

covering the entire heart in the left ventricular short-axis and additional long-axis sections. Cine CMR is the most accurate imaging method for the measurement of left and right heart dimensions and contractile function. In later stages of cardiac sarcoidosis, contractile function can be impaired and is sensitively detected and followed up with CMR. Cine CMR also allows detection of ventricular aneurysms, pericardial effusion, and valve pathology. Increasingly, parametric T1 and T2 mapping provide quantitative measures of tissue inflammation, oedema, and diffuse fibrosis, but are only beginning to be used in sarcoidosis, so that, experience with these newer methods is limited.

\section{Interpretation and Reporting}

The most commonly found CMR abnormality in patients with sarcoidosis is focal hyperenhancement on LGE images, usually readily detectable by visual inspection. Mid-wall or sub-epicardial enhancement in the basal ventricular wall, the lateral wall, and septum is considered the most common pattern in cardiac sarcoidosis, but subendocardial or transmural enhancement in other myocardial locations has also been described ${ }^{82}$ (Figure 3). Importantly, LGE findings are not specific to sarcoidosis and the differential diagnosis from myocarditis and other inflammatory conditions can be

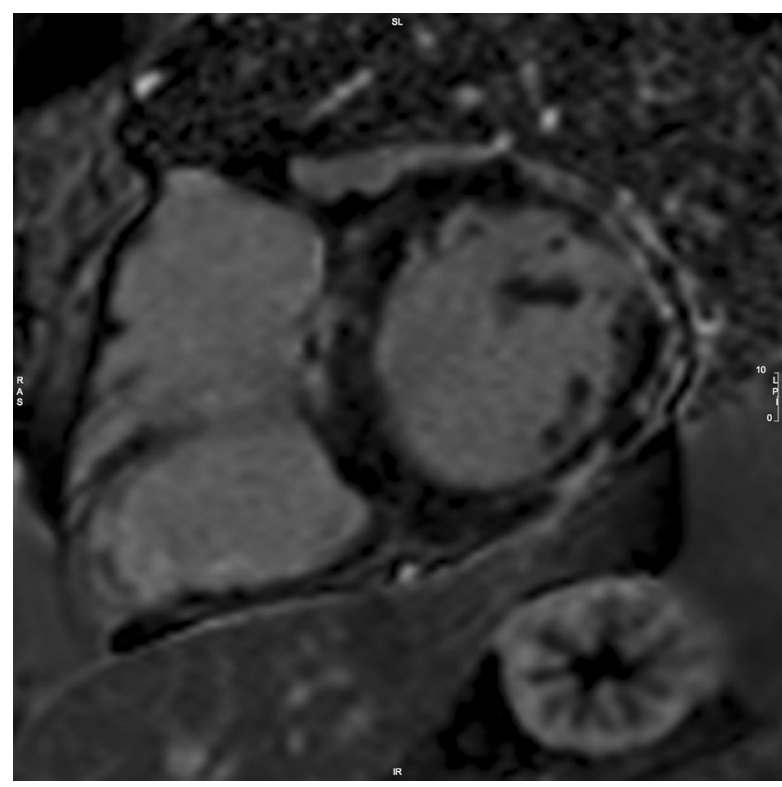

Figure 3. Example of cardiac sarcoidosis diagnosed with CMR. Late gadolinium enhanced CMR image from an AfroCaribbean male who presented with pulmonary sarcoidosis and suspected cardiac involvement. The image shows focal midmyocardial contrast enhancement in the basal inferior and lateral wall and septum (image courtesy Dr. Tevfik Ismail, King's College London, UK). 
challenging. Using thresholding methods, the extent of hyperenhancement on LGE can be quantified to give a measure of disease extent, but no consensus exists so far to the optimal threshold for diagnosis. Oedema sensitive images may show areas of high signal in patients with cardiac sarcoidosis, suggestive of inflammation, and oedema. However, reliable detection of oedema can be difficult as T2 weighted images have a relatively low signal to noise ratio and can be prone to artifacts, in particular from slow flow at the endocardial boundary. A careful review of the images is therefore mandatory. By calculating the ratio of signal in skeletal muscle and the myocardium, a semi-quantitative measure of oedema can be derived. In sarcoidosis, cine CMR provides quantitative measurements of volumes and $\mathrm{EF}$ and shows similar abnormalities as seen on 2D echocardiography. A CMR report in suspected sarcoidosis should include a description of extracardiac findings (including lung nodules, splenic or hepatic perfusion defects), measurements of right and left ventricular size, volumes, and function, comments on pericardial and valve pathology, presence of oedema, and a description of the location and size of lesions seen on LGE.

\section{Diagnostic Accuracy}

Multi-parametric CMR is a sensitive tool for the detection of cardiac involvement in sarcoidosis. However, to date CMR has only been used in relatively small observational studies and as for other imaging modalities, prospectively designed diagnostic accuracy studies against histological endpoints are lacking. Similar to FDG-PET studies, estimates of the diagnostic accuracy of CMR in cardiac sarcoidosis are hampered by the lack of a gold standard.

The first report on the diagnostic accuracy of CMR for cardiac sarcoidosis showed a sensitivity of $100 \%$ and specificity of $78 \%$ vs the JMHW criteria. ${ }^{80}$ The relatively low specificity can be explained, as the CMR data were compared using the low diagnostic sensitive JMHW criteria. Patel et al, showed that CMR compared with the JMHW criteria resulted in a higher incidence of cardiac involvement in sarcoidosis (i.e., >2-fold increase in cardiac sarcoidosis diagnosis vs JMHW criteria), leading to a significant improvement in prognostication of adverse events by CMR when compared with JMHW criteria. $^{82}$

The most consistently reported finding on CMR is focal LGE, described in numerous smaller reports ${ }^{7,77-81}$ and two larger studies, which found LGE in 39 of 155 $(25.5 \%)$ and 41 of $205(20 \%)$ patients with extracardiac sarcoidosis, ${ }^{76,83}$ and a systematic review and meta- analysis. ${ }^{84}$ Importantly, LGE was seen in patients who did not meet standard JMHW guidelines, suggesting that CMR is a more sensitive test to detect cardiac involvement in sarcoidosis than established diagnostic criteria, however, specificity may be variable. Although small reports have suggested that some lesions on LGE regress following steroid therapy, ${ }^{85}$ this needs to be further evaluated.

Oedema sensitive T2 weighted imaging and T2 mapping have only been used in cases series and small feasibility studies. In 32 patients with sarcoidosis, increased signal in the interventricular septum on T2weighted images was more common in patients with complete heart block than patients with normal conduction. $^{74}$ T2 mapping has been used in a study of 28 patients and showed reduced $\mathrm{T} 2$ values in regions of LGE, which the authors speculate may reflect an inactive phase of the disease. ${ }^{86}$

The above limitations related to evaluating the diagnostic accuracy of CMR, similar to the ones for FDG-PET underscore the importance of evaluating the prognostic findings provided by various imaging results, as the ultimate identification of patients who have a higher risk of adverse events may be most important for guiding therapy. Finally, as discussed in 'Approach to Sarcoidosis Imaging Procedures' section, with the exception of a few small reports, focal LGE by CMR has consistently been linked with adverse clinical outcome. $^{76,77,87,88}$

Of equal importance, the absence of LGE in patients with suspected cardiac sarcoidosis is generally associated with a favorable prognosis, ${ }^{76}$ although some studies have shown conflicting findings. ${ }^{77}$

In summary, CMR is a multi-parametric imaging modality that can accurately delineate cardiac morphology and function and interrogate tissue characteristics. CMR is a valuable tool for the diagnosis and risk assessment of cardiac sarcoidosis. Whether CMR can be used to assess response to therapy is unclear, as CMR findings are limited by a relatively low specificity to distinguish scar from active inflammation. However, the relatively high sensitivity of the technique contributes to the exclusion of cardiac sarcoidosis.

\section{COMPUTED TOMOGRAPHY}

CT plays a limited role in the evaluation and management of patients with systemic sarcoidosis. Although, cardiac CT has no established role for the diagnosis of cardiac sarcoidosis, coronary CT angiography may play an important role in excluding CAD in individuals with $\mathrm{LV}$ dysfunction and regional wall motion abnormalities. 


\section{A Baseline}

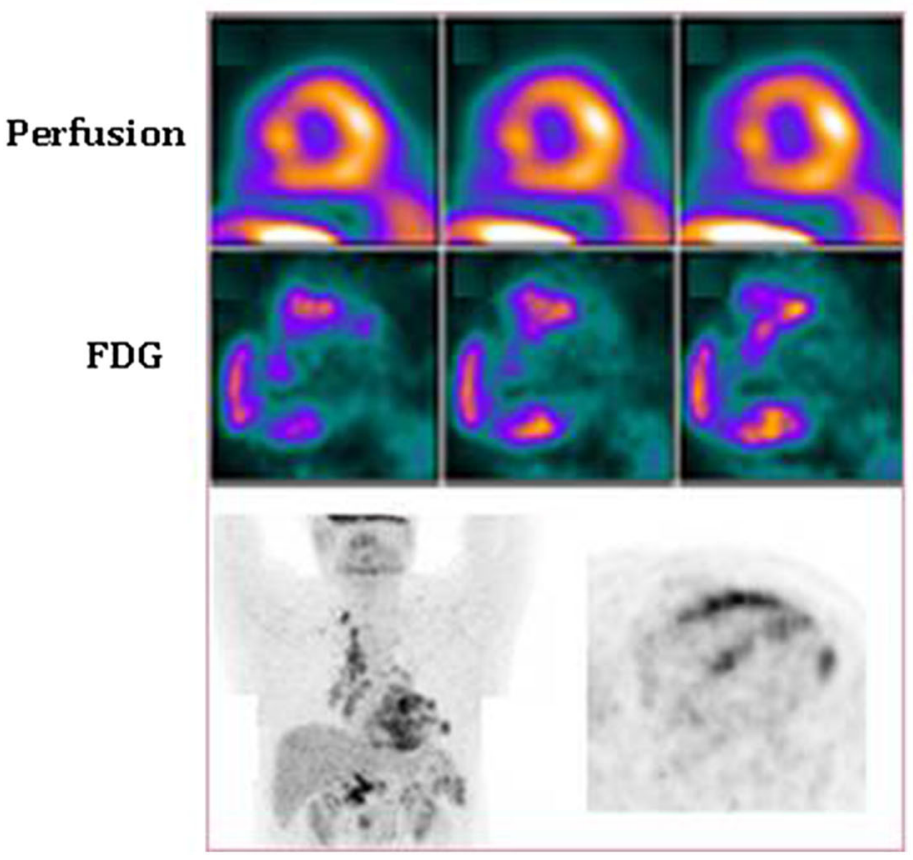

B Post therapy

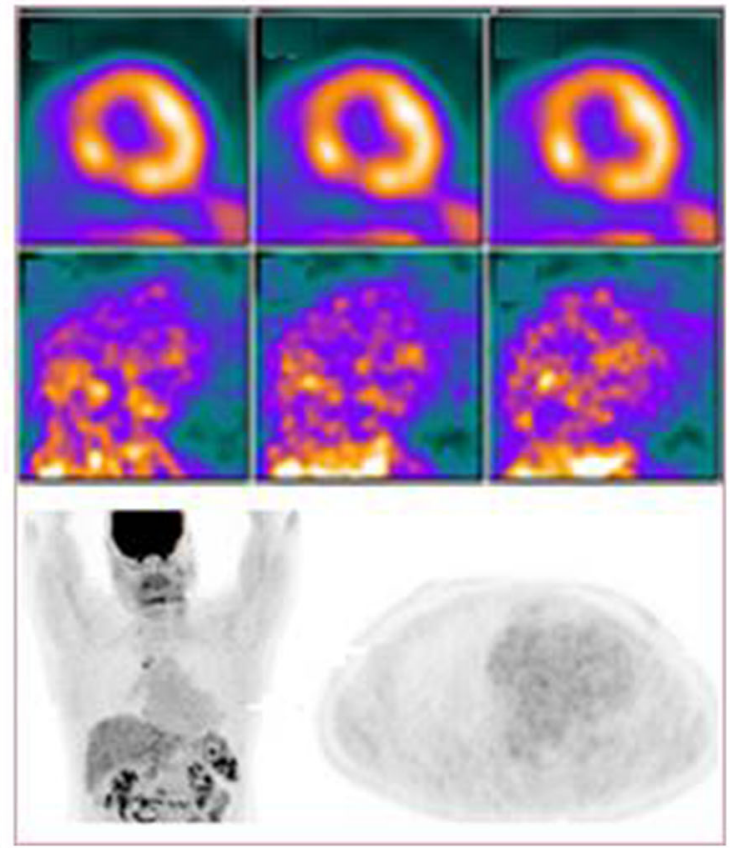

Figure 4. Example of FDG and myocardial perfusion PET in sarcoidosis: assessing response to therapy with FDG-PET. A 48-year-old man with mild exertional dyspnea with exercise that progressed to more severe dyspnea and with lightheadedness and dizziness. His ECG should complete heart block with ventricular escape rate of $45 \mathrm{bpm}$, catheterization revealed no coronary artery disease, and his left ventricular ejection fraction was 52\%. A cardiac MRI suggested four areas of inflammatory/infiltrative processes in the basal septal and anteroseptal regions. A CT scan of the chest revealed enlarged mediastinal lymph nodes and bilateral pulmonary nodules. An endomyocardial biopsy showed non-specific mild hypertrophy. A mediastinoscopy with biopsy of a mediastinal lymph nodes confirmed extensive (confluent) non-necrotizing granulomas consistent with sarcoidosis. An FDG-PET scan was performed prior to initiation of prednisone therapy. It revealed multiple foci of inflammation in the left and right ventricular walls ( $\mathrm{SUV}_{\max }$ 5.7) as well as in the mediastinum. Oral prednisone $40 \mathrm{mg} \cdot \mathrm{day}^{-1}$ was initiated and an ICD was implanted. Three months after high-dose steroid therapy, a repeat FDG-PET scan showed that myocardial $\left(\mathrm{SUV}_{\max } 1.5\right)$ and mediastinal inflammation is substantially decreased (blood pool FDG activity is noted), but splenic and abdominal lymph node inflammation persisted. No myocardial perfusion defects were noted suggesting no regions of fibrosis.

\section{IMAGING TO GUIDE BIOPSY}

Cardiac involvement is often difficult to diagnose because endomyocardial biopsy is limited by sampling error and complication risk cannot be ignored. ${ }^{45,89,90}$ The diagnosis of isolated cardiac involvement is therefore difficult and laboratory abnormalities are non-specific. If the likelihood of an inflammatory cardiomyopathy remains high despite a negative endomyocardial biopsy, pursuing the diagnosis with repeated and image-guided biopsies of the myocardium or mediastinal lymph nodes is worthwhile and may markedly improve the detection rate of cardiac sarcoidosis. ${ }^{91}$ Biopsy guided by electromechanical mapping has also been used for the diagnosis of isolated cardiac sarcoidosis. ${ }^{92}$ Although focal myocardial LGE, high T2 signal on CMR, and increased glucose uptake on cardiac FDG-PET are non- specific signs of myocardial damage or inflammation, in patients with histologically proven extracardiac sarcoidosis, they provide sensitive signs of sarcoid involvement of the heart. ${ }^{54,82}$ In patients with biopsyproven cardiac sarcoidosis, abnormal LGE and FDGPET findings were observed in $94 \%$ and $80 \%$ of patients, respectively. ${ }^{91}$ However, without histopathological verification, even typical abnormalities on CMR or PET may not provide a definitive diagnosis and decisions regarding long-term immunosuppression in such patients with suspected, but not proven, cardiac sarcoidosis remains challenging and must be individualized. The role of hybrid PET/CT and PET/MRI to guide biopsy remains to be evaluated (see 'Future Directions' section).

In summary, abnormal cardiac findings on CMR and/or FDG-PET are frequent and suggest localized 
Table 5. Summary of studies examining the prognostic value of CMR and FDG-PET in cardiac sarcoidosis

\begin{tabular}{|c|c|c|c|c|c|c|}
\hline Study & $\begin{array}{l}\text { Number/ } \\
\text { type of } \\
\text { patients }\end{array}$ & $\begin{array}{l}\text { Patients } \\
\text { with } \\
\text { abnormal } \\
\text { LGE/PET } \\
\text { N (\%) }\end{array}$ & $\begin{array}{c}\text { Median } \\
\text { F/U } \\
\text { (months) }\end{array}$ & $\begin{array}{c}\text { Overall } \\
\text { number } \\
\text { of events }\end{array}$ & $\begin{array}{l}\text { Number of } \\
\text { events in } \\
\text { patients } \\
\text { without LGE/ } \\
\text { normal PET }\end{array}$ & Conclusions \\
\hline $\begin{array}{l}\text { Patel } \\
\quad \text { et } \mathrm{al}^{82}\end{array}$ & $\begin{array}{l}81 \mathrm{w} / \\
\text { extracardiac } \\
\text { disease }\end{array}$ & $21(26)$ & 21 & $\begin{array}{l}8 \text { (5 Death, } \\
2 \text { VT, } 1 \text { AVB) }\end{array}$ & $\begin{array}{l}2 \text { (1 Cardiac } \\
\text { death; } 1 \text { non- } \\
\text { cardiac death) }\end{array}$ & $\begin{array}{l}\text { (+) CMR associated } \\
\text { with events; more } \\
\text { sensitive than } \\
\text { clinical criteria }\end{array}$ \\
\hline $\begin{array}{l}\text { Greulich } \\
\text { et al }^{76}\end{array}$ & $\begin{array}{l}155 \mathrm{w} / \\
\text { extracardiac } \\
\text { disease }\end{array}$ & $39(25)$ & 31 & $\begin{array}{l}12 \\
\text { (Death/ } \\
\text { SCD/ICD Rx) }\end{array}$ & $\begin{array}{l}1 \text { (1 Non-cardiac } \\
\text { death) }\end{array}$ & $\begin{array}{l}(+) \mathrm{CMR} \text { is a strong } \\
\text { predictor of } \\
\text { potentially lethal } \\
\text { events }\end{array}$ \\
\hline $\begin{array}{l}\text { Nagai } \\
\quad \text { et } \mathrm{al}^{77}\end{array}$ & $\begin{array}{l}61 \mathrm{w} / \text { extracardiac } \\
\text { disease }\end{array}$ & $8(13)$ & 50 & 1 (1 AVB) & $\begin{array}{l}2 \text { ( } 2 \text { Non- } \\
\text { cardiac death) }\end{array}$ & $\begin{array}{l}\text { Both patients with } \\
\text { and w/out LGE } \\
\text { had low event rates }\end{array}$ \\
\hline $\begin{array}{l}\text { Nadel } \\
\quad \text { et } \text { al }^{95}\end{array}$ & $\begin{array}{l}106 \mathrm{w} / \\
\text { extracardiac } \\
\text { or cardiac } \\
\text { disease }\end{array}$ & $32(30)$ & 37 (mean) & $\begin{array}{l}4 \text { SCD } \\
8 \mathrm{VT} / \mathrm{VF} \\
\text { (8 no cardiac } \\
\text { deaths) }\end{array}$ & 1 (1 SCD) & $\begin{array}{l}\text { LGE } \rightarrow \text { higher rate } \\
\text { of SCD/VT/VF } \\
\text { ICD in cardiac sarcoidosis } \\
\rightarrow \text { associated with lower } \\
\text { mortality }\end{array}$ \\
\hline $\begin{array}{l}\text { Murtagh } \\
\text { et }^{8 l^{83}}\end{array}$ & $\begin{array}{l}205 \mathrm{w} / \\
\text { extracardiac } \\
\text { disease and } \\
\mathrm{EF}>50 \%\end{array}$ & $41(20)$ & 36 (Mean) & $\begin{array}{l}12 \text { Death/VT } \\
\text { (8 deaths; } \\
4 \text { VT) }\end{array}$ & 2 (2 Deaths) & $\begin{array}{l}\mathrm{LGE} \rightarrow \text { higher rate } \\
\text { of death/VT, even } \\
\text { with preserved EF }\end{array}$ \\
\hline $\begin{array}{l}\text { Blankstein } \\
\quad \text { et } \mathrm{al}^{45}\end{array}$ & $\begin{array}{l}118 \mathrm{w} / \\
\text { extracardiac } \\
\text { disease }\end{array}$ & $37(31)$ & 18 & $\begin{array}{l}31 \text { ( } 27 \mathrm{VT} \text { and } \\
8 \text { deaths) }\end{array}$ & $\begin{array}{l}4 \text { VT events and } 3 \\
\text { deaths, } 1 \text { in a } \\
\text { patient who } \\
\text { also had VT }\end{array}$ & $\begin{array}{l}\text { Focal PD and FDG } \\
\text { uptake on cardiac } \\
\text { PET identifies patients } \\
\text { at higher risk of } \\
\text { death or VT }\end{array}$ \\
\hline $\begin{array}{l}\text { Ahmadian } \\
\text { et }^{4 l^{44}}\end{array}$ & $\begin{array}{l}34 \mathrm{w} / \\
\text { extracardiac } \\
\text { disease }\end{array}$ & $23(61)$ & 3 & $\begin{array}{l}11 \mathrm{VT}, \mathrm{AVB}, \\
\text { heart failure }\end{array}$ & 1 & $\begin{array}{l}\text { Quantification of FDG } \\
\text { uptake in CS by } \\
\text { CMA is an important } \\
\text { tool for prognostication } \\
\text { in patients with known } \\
\text { or suspected cardiac } \\
\text { sarcoidosis }\end{array}$ \\
\hline
\end{tabular}

$C S$, cardiac sarcoidosis, $P D$, perfusion defects, $L G E$, late gadolinium enhancement, $V T$, ventricle tachycardia, $V F$, ventricle fibrillation, $S C D$, sudden cardiac death, $A V B$, atrio-ventricular block, $I C D$, implantable cardioverter defibrillators, $E F$, ejection fraction, $C M A$, cardiac metabolic activity

areas of myocardial damage and/or inflammation in patients with cardiac sarcoidosis. In a clinical setting suggestive of cardiac sarcoidosis, 'hot' mediastinal or cervical lymph nodes on FDG-PET provide a biopsy target that may improve the success rate of identifying sarcoid histopathology. The potential role of imageguided endomyocardial biopsy to improve the yield for histopathological diagnosis of cardiac sarcoidosis requires further evaluation.

\section{IMAGING TO INITIATE AND MONITOR THERAPY}

Immunosuppressive therapy is frequently used to treat cardiac sarcoidosis. Sarcoidosis experts, using a Delphi study method, agreed on the treatment of cardiac sarcoidosis with immunosuppressive therapy for the following clinical scenarios: LV dysfunction, ventricular arrhythmias, hypermetabolic activity on cardiac FDGPET, presence of conduction defects, LGE on CMR, or right ventricular dysfunction in the absence of pulmonary hypertension. ${ }^{93}$ But, due to high side effect profile of immunosuppressive drugs, image-guided initiation and tailoring of therapy are critical.

A multimodality imaging approach may be necessary for the decision making about pacemaker or ICD. ${ }^{10}$ Per HRS guidelines, ${ }^{10}$ ICD is indicated, if LVEF remains $<35 \%$ after immunosuppressive therapy (Class I) or if LGE is present in patients with LVEF 35\%-49\% after immunosuppression (Class IIb).

Echocardiography and/or CMR features are not very specific for inflammation. However, they may help in the assessment of LV remodeling, left as well as right ventricular function, pulmonary artery hypertension, and in the follow-up of end stage heart failure from cardiac sarcoidosis before and after heart transplantation. ${ }^{25}$ The 


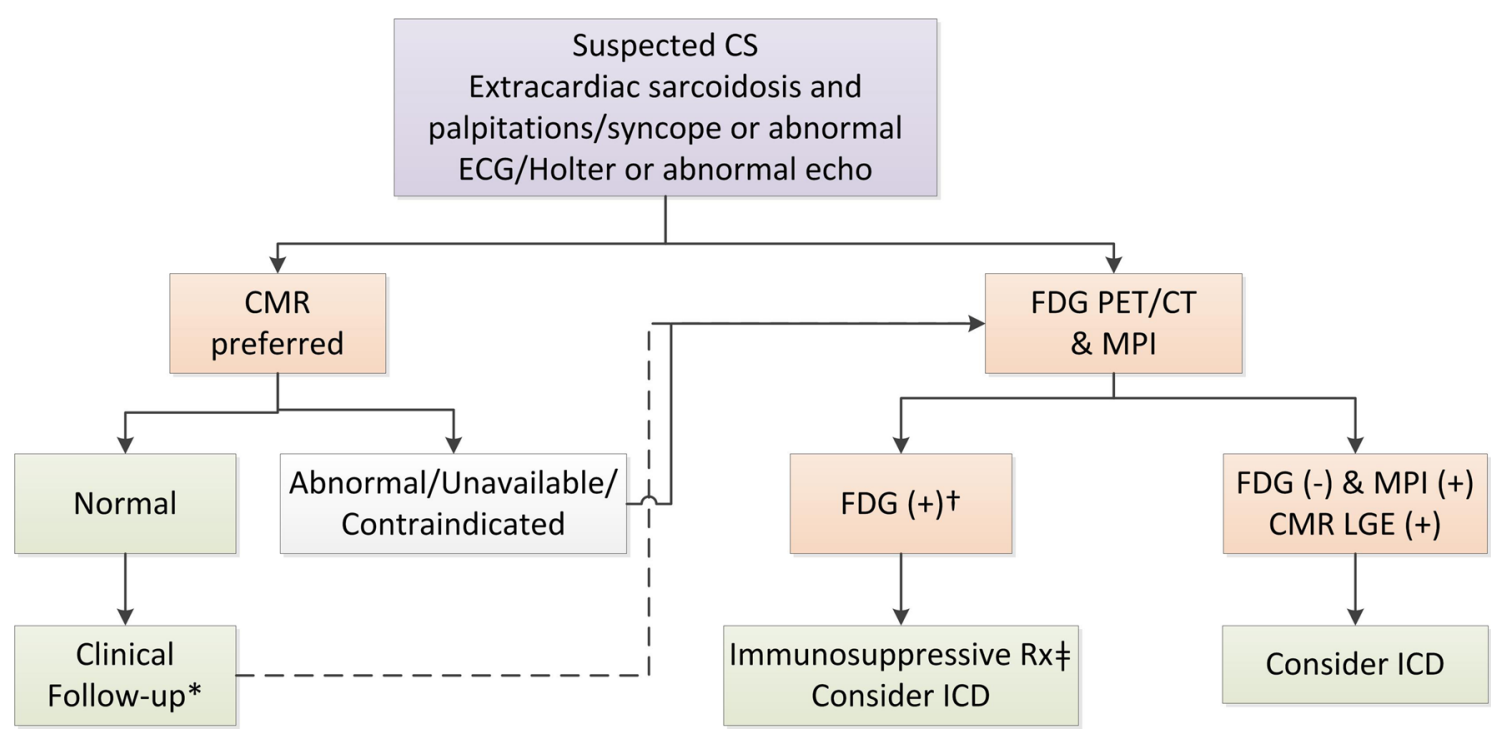

Figure 5. Non-invasive imaging approach to initial evaluation of patients with suspected cardiac sarcoidosis. $C S$, cardiac sarcoidosis, $C M R$, cardiovascular magnetic resonance imaging, $E C G$, electrocardiogram, Echo, echocardiogram, $F D G,{ }^{18} \mathrm{~F}$-fluorodeoxyglucose, $I C D$, implantable cardioverter defibrillator, $L G E$, late gadolinium enhancement, $M P I$,myocardial perfusion imaging, $R x$, therapy. ${ }^{\dagger}$ Identify coexistent inflammation; FDG-PET/CT may be preferred first test in individuals with known systemic sarcoidosis where systemic sarcoidosis activity needs to be assessed. *If clinical suspicion is high or symptoms persist, FDG-PET/CT and MPI may be considered in patients with normal CMR. ${ }^{+}$Immunosuppressive Rx may be considered taking into account the amount of inflammation. Patients with ICD are excluded for CMR.

use of echocardiography and CMR (and LGE) to assess changes in inflammation in response to therapy is limited. ${ }^{94}$

Observational studies suggest an important role for FDG-PET to monitor efficacy of immunosuppressive therapy. ${ }^{53}$ Osborne et al examined 23 patients who underwent serial FDG-PET exams during treatment for cardiac sarcoidosis. They showed that a quantitative reduction in the intensity (i.e., $\mathrm{SUV}_{\max }$ ) or extent (i.e., volume of inflammation above a pre-specified SUV threshold) was associated with improvement in LVEF. ${ }^{59}$ Although clear response to therapy is seen in some case (Figure 4), the use of visual analysis to assess serial changes in response to therapy may be limited particularly when there is partial response (see 'Myocardial perfusion imaging' section). Quantitative metrics of $\mathrm{SUV}_{\max }$ as well as volume of myocardial pixels with SUV above a certain threshold, and changes in extent and severity of myocardial perfusion, may be preferred to assess response to therapy. Whether steroid induced glucose metabolic changes influence FDG uptake by the myocardium is not known. The duration of treatment is based on clinical response and can be guided by disease activity on FDG-PET, Figure $6 .^{88}$ The optimal timing to repeat FDG-PET imaging is not known. We suggest repeating FDG-PET approximately 4-6 months after initiation of therapy.
In summary, in the absence of specific guidelines, in asymptomatic patients with cardiac sarcoidosis, echocardiography is useful to follow-up LVEF and to evaluate for new wall motion abnormalities, wall thinning. A quantitative FDG-PET with MPI may be useful to monitor progression of scar and inflammation and assess response to active immunosuppressive therapies. Prospective randomized clinical trials of imaging guided management of immunosuppressive therapy are warranted.

\section{PROGNOSIS}

Several groups of investigators have studied the value of structural and functional myocardial changes of cardiac sarcoidosis detected on echocardiography, CMR, and FDG-PET in predicting prognosis (Table 5). The extent of LV dysfunction and dilatation at baseline are important predictors of survival. ${ }^{23}$ Further, a reduced global longitudinal strain is an independent predictor of adverse events among patients with suspected cardiac sarcoidosis. ${ }^{25}$ The presence of LGE on CMR, including focal LGE, ${ }^{76}$ and the extent of LGE (LGE mass $\geq 20 \%$ of LV mass), is associated with a higher risk of death or VT and a lower likelihood of improvement in LV function. ${ }^{83,99}$ The prognostic value of other CMR 
findings have been less well studied and no reports are available for T2 weighted CMR. In one study, LVEF was a weaker prognosticator than LGE. ${ }^{83}$ Importantly, patients who do not have any late enhancement had an extremely low event rate, with very few cardiac events reported. Therefore, CMR may be used not only to exclude the presence of cardiac sarcoidosis in the vast majority of patients with suspected disease, but also to identify patients who have an excellent prognosis, with a strong value of LGE. Also, patients with a combination of (a) increased myocardial inflammation (i.e., focal uptake of FDG) and (b) resting perfusion defects are at high risk for death or VT (4-fold increased risk), ${ }^{45}$ independent of LVEF, clinical criteria, and the presence of active extracardiac disease. ${ }^{44,45}$ In addition, the presence of focal uptake of FDG by the right ventricle was found to be associated with an extremely high event rate. Notably, the presence or absence of active extracardiac sarcoidosis was not associated with adverse events.

Based on the published studies to date, the event rate in patients referred for cardiac PET is higher than those referred for CMR. This difference can be explained by the fact that patients referred for PET are more likely to already have an ICD (which is sometimes a contraindication for CMR) and prior history of VT. Therefore, this most likely reflects a referral bias based on the fact that patients referred for PET imaging have higher degree of disease activity. ${ }^{97,98}$

In summary, while there is a paucity of data in this regard, it seems plausible that the findings provided by echocardiography (which provides an estimate of myocardial remodeling and function), CMR (which provides an estimate of the extent of scar), PET imaging with FDG (which provide an estimate of the overall magnitude and extent of myocardial inflammation), and MPI (which provides an estimate of microvascular dysfunction and/or scar) may be complementary, both for diagnosing and treating disease, as well as for providing an estimate of the risk of future adverse events.

\section{APPROACH TO SARCOIDOSIS IMAGING PROCEDURES}

The approach to cardiac sarcoidosis imaging may include multiple imaging tests (Figure 5). The main indications for advanced imaging in cardiac sarcoidosis: (i) suspected cardiac involvement in patients with biopsy-proven extracardiac sarcoidosis and symptoms (unexplained syncope/presyncope/significant palpitations), and/or abnormal ECG and/or inconclusive echocardiogram $^{10}$; (ii) suspected relapse in a patient with a history of cardiac sarcoidosis; (iii) treatment

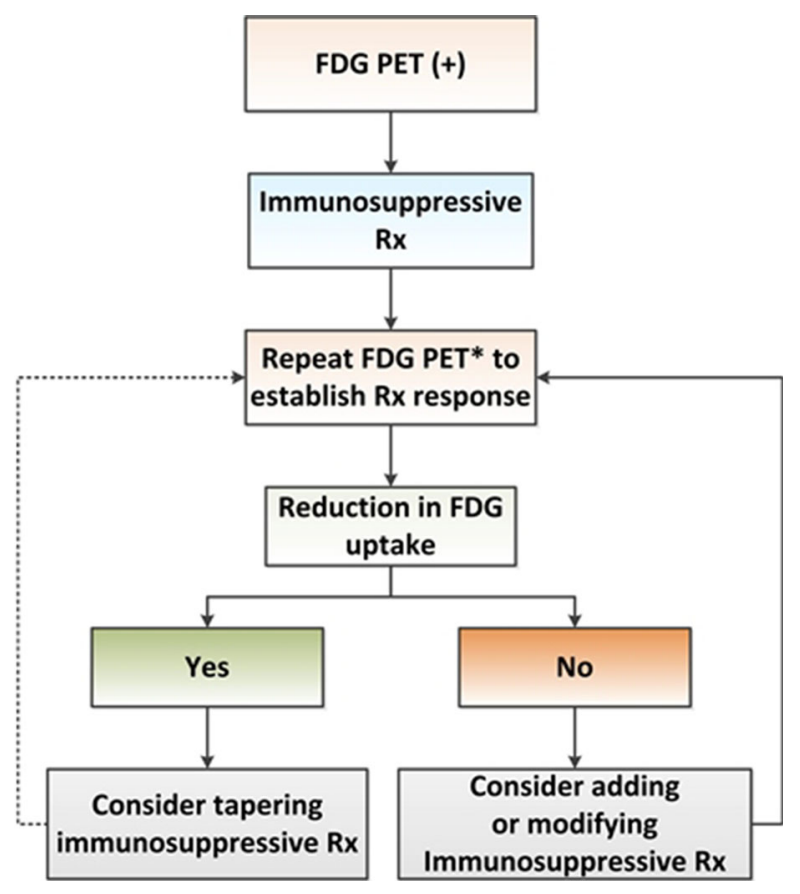

Figure 6. Use of FDG-PET imaging to guide immunosuppressive therapy in cardiac sarcoidosis. In cardiac sarcoidosis patients with positive FDG-PET imaging, repeat FDG-PET imaging can be repeated to judge treatment response, however, whether the result of FDG-PET can be used to taper immunosuppressive therapy is currently unclear and evidence is lacking to adjust treatment based on imaging. *The optimal timing of repeat FDG-PET imaging is not well established, but approximately 4-6 months following treatment initiation is commonly employed, or when significant changes in therapy are being considered. FDG, ${ }^{18}$ F-fluorodeoxyglucose; Rx, therapy.

monitoring in patients diagnosed with cardiac sarcoidosis. In addition, advanced imaging may contribute to (iv) prognostic assessment that may impact on therapeutic management and follow-up. ${ }^{19,99,100}$ Radionuclide imaging, particularly FDG-PET with SUV quantitation and in conjunction with MPI, may be useful to not only detect myocardial inflammation but also to monitor progression of scar and inflammation and assess response to active immunosuppressive therapies (Figure 6).

\section{FUTURE DIRECTIONS}

The future of cardiac sarcoidosis imaging relies on development of novel inflammation specific radiotracers, hybrid imaging devices, as well as multidisciplinary, and multiinstitutional collaborations using standardized imaging methods. Novel somatostatin receptor binding radiopharmaceuticals such as ${ }^{68} \mathrm{Ga}$-DOTATOC/TATE/ NOC, radiotracers of inflammation $\left({ }^{11} \mathrm{C}-\mathrm{PBR} 28\right)$, and ${ }^{18}$ F-FLT (fluorothymidine) as well as novel CMR contrast agents such as Ferumoxytol (contrast agent 
consisting of ultrasmall superparamagnetic particles of iron oxide that are taken up by macrophages, are under evaluation (http://www.clinicaltrials.gov). In addition, novel hybrid imaging systems combining PET and MRI (PET/MRI camera) provide highly complementary information on tissue characterization and metabolic information in one single session. ${ }^{101,102}$ Due to the lack of a gold standard for the diagnosis of cardiac sarcoidosis, the lack of specificity of the imaging findings, and the potential risk of high-dose immunosuppressive therapies, sarcoidosis is challenging to diagnose and manage. A multidisciplinary heart team approach involving experienced imagers (echocardiography, CMR, and radionuclide imaging), internal medicine physicians, cardiologists, heart failure physicians, pulmonary physicians, electrophysiologists, rheumatologists, pathologists, and others will be critical to manage sarcoidosis.

\section{CONCLUSIONS}

Sarcoidosis is a complex systemic disease that often requires multidisciplinary expertise and approach for diagnosis and management. Detection of cardiac sarcoidosis is important to prevent life-threatening arrhythmias and to preserve LV function in affected individuals. A multi-imaging approach that can identify disease activity, prognosis, and response to therapy is needed to improve further the management of patients with cardiac sarcoidosis. Optimal imaging based on standardized procedural guidelines for acquisition, interpretation, and quantification is paramount.

\section{SUPPLEMENTARY DATA}

Supplementary data are available at Journal of Nuclear Cardiology online.

\section{Disclosures}

Riemer H.J.A. Slart, Andor W.J.M. Glaudemans, Patrizio Lancellotti, Fabien Hyafil, Ron Blankstein, Ronald G. Schwartz, Wael A. Jaber, Raymond Russell, Alessia Gimelli, François Rouzet, Marcus Hacker, Olivier Gheysens, Sven Plein, Edward J. Miller, Sharmila Dorbala, and Erwan Donal declare that they have no conflicts of interest to disclose.

\section{References}

1. Ungprasert P, Carmona EM, Utz JP, Ryu JH, Crowson CS, Matteson EL. Epidemiology of sarcoidosis 1946-2013: A population-based study. Mayo Clin Proc 2016;91:183-8.

2. Baughman RP, Teirstein AS, Judson MA, Rossman MD, Yeager $\mathrm{H} \mathrm{Jr}$, Bresnitz EA. Clinical characteristics of patients in a case control study of sarcoidosis. Am J Respir Crit Care Med 2001;164:1885-9.

3. Lynch JP III, Hwang J, Bradfield J, Fishbein M, Shivkumar K, Tung R. Cardiac involvement in sarcoidosis: Evolving concepts in diagnosis and treatment. Semin Respir Crit Care Med 2014;35:372-90.

4. Perry A, Vuitch F. Causes of death in patients with sarcoidosis. A morphologic study of 38 autopsies with clinicopathologic correlations. Arch Pathol Lab Med 1995;119:167-72.

5. Silverman KJ, Hutchins GM, Bulkley BH. Cardiac sarcoid: A clinicopathologic study of 84 unselected patients with systemic sarcoidosis. Circulation 1978;58:1204-11.

6. Nelson JE, Kirschner PA, Teirstein AS. Sarcoidosis presenting as heart disease. Sarcoidosis Vasc Diffuse Lung Dis 1996;13:17882.

7. Kim JS, Judson MA, Donnino R, Gold M, Cooper LT Jr, Prystowsky EN. Cardiac sarcoidosis. Am Heart J 2009;157:9-21.

8. Yazaki Y, Isobe M, Hiroe M, Morimoto S, Hiramitsu S, Nakano T. Prognostic determinants of long-term survival in Japanese patients with cardiac sarcoidosis treated with prednisone. Am J Cardiol 2001;88:1006-10.

9. Japanese Ministry Health Welfare. Diagnostic standard and guidelines for sarcoidosis. Jpn J Sarcoidosis Granulomatous Disord (Jpn) 2007;27:89-102.

10. Birnie DH, Sauer WH, Bogun F, Cooper JM, Culver DA, Duvernoy CS. HRS Expert Consensus Statement on the diagnosis and management of arrhythmias associated with cardiac sarcoidosis. Heart Rhythm 2014;11:1305-23.

11. Cardim N, Galderisi M, Edvardsen T, Plein S, Popescu BA, D'andrea A. Role of multimodality cardiac imaging in the management of patients with hypertrophic cardiomyopathy: An Expert Consensus of the European Association of Cardiovascular Imaging Endorsed by the Saudi Heart Association. Eur Heart J Cardiovase Imaging 2015;16:280.

12. Cosyns B, Plein S, Nihoyanopoulos P, Smiseth O, Achenbach S, Andrade MJ. European Association of Cardiovascular Imaging (EACVI) position paper: Multimodality imaging in pericardial disease. Eur Heart J Cardiovasc Imaging 2014;16:12-31.

13. Flachskampf FA, Wouters PF, Edvardsen T, Evangelista A, Habib G, Hoffman P. Recommendations for transoesophageal echocardiography: EACVI update 2014. Eur Heart J Cardiovasc Imaging 2014;15:353-65.

14. Lancellotti P, Tribouilloy C, Hagendorff A, Popescu BA, Edvardsen T, Pierard LA. Recommendations for the echocardiographic assessment of native valvular regurgitation: An executive summary from the European Association of Cardiovascular Imaging. Eur Heart J Cardiovasc Imaging 2013;14:611-44.

15. Lang RM, Badano LP, Tsang W, Adams DH, Agricola E, Buck T. EAE/ASE recommendations for image acquisition and display using three-dimensional echocardiography. Eur Heart J Cardiovasc Imaging 2012;13:1-46.

16. Lang RM, Badano LP, Mor-Avi V, Afilalo J, Armstrong A, Ernande L. Recommendations for cardiac chamber quantification by echocardiography in adults: An update from the American Society of Echocardiography and the European Association of Cardiovascular Imaging. Eur Heart J Cardiovasc Imaging 2015;16:233-70.

17. Mor-Avi V, Lang RM, Badano LP, Belohlavek M, Cardim NM, Derumeaux G. Current and evolving echocardiographic techniques for the quantitative evaluation of cardiac mechanics: ASE/ EAE Consensus Statement on methodology and indications endorsed by the Japanese Society of Echocardiography. J Am Soc Echocardiogr 2011;24:277-313. 
18. Popescu BA, Stefanidis A, Nihoyannopoulos P, Fox KF, Ray S, Cardim N. Updated standards and processes for accreditation of echocardiographic laboratories from The European Association of Cardiovascular Imaging: An executive summary. Eur Heart J Cardiovasc Imaging 2014;15:1188-93.

19. Aggarwal NR, Snipelisky D, Young PM, Gersh BJ, Cooper LT, Chareonthaitawee P. Advances in imaging for diagnosis and management of cardiac sarcoidosis. Eur Heart J Cardiovasc Imaging 2015;16:949-58.

20. Focardi M, Picchi A, Nikiforakis N, Bargagli E, Fossi A, Maggiorelli C. Assessment of cardiac involvement in sarcoidosis by echocardiography. Rheumatol Int 2009;29:1051-5.

21. Lewin RF, Mor R, Spitzer S, Arditti A, Hellman C, Agmon J. Echocardiographic evaluation of patients with systemic sarcoidosis. Am Heart J 1985;110:116-22.

22. Burstow DJ, Tajik AJ, Bailey KR, DeRemee RA, Taliercio CP. Two-dimensional echocardiographic findings in systemic sarcoidosis. Am J Cardiol 1989;63:478-82.

23. Chiu CZ, Nakatani S, Zhang G, Tachibana T, Ohmori F, Yamagishi M. Prevention of left ventricular remodeling by long-term corticosteroid therapy in patients with cardiac sarcoidosis. Am J Cardiol 2005;95:143-6.

24. Jain A, Starek PJ, Delany DL. Ventricular tachycardia and ventricular aneurysm due to unrecognized sarcoidosis. Clin Cardiol 1990;13:738-40.

25. Patel MB, Mor-Avi V, Murtagh G, Bonham CA, Laffin LJ, Hogarth DK. Right heart involvement in patients with sarcoidosis. Echocardiography 2016;33:734-41.

26. Vasaiwala SC, Finn C, Delpriore J, Leya F, Gagermeier J, Akar JG. Prospective study of cardiac sarcoid mimicking arrhythmogenic right ventricular dysplasia. J Cardiovasc Electrophysiol 2009;20:473-6.

27. Degirmenci H, Demirelli S, Arisoy A, Ermis E, Araz O, Bakirci EM. Myocardial deformation and total atrial conduction time in the prediction of cardiac involvement in patients with pulmonary sarcoidosis. Clin Respir J 2017;11:68-77.

28. Joyce E, Ninaber MK, Katsanos S, Debonnaire P, Kamperidis V, Bax JJ. Subclinical left ventricular dysfunction by echocardiographic speckle-tracking strain analysis relates to outcome in sarcoidosis. Eur J Heart Fail 2015;17:51-62.

29. Kul S, Ozcelik HK, Uyarel H, Karakus G, Guvenc TS, Yalcinsoy M. Diagnostic value of strain echocardiography, galectin-3, and tenascin-C levels for the identification of patients with pulmonary and cardiac sarcoidosis. Lung 2014;192:533-42.

30. Orii M, Hirata K, Tanimoto T, Shiono Y, Shimamura K, Yamano T. Myocardial damage detected by two-dimensional speckletracking echocardiography in patients with extracardiac sarcoidosis: Comparison with magnetic resonance imaging. J Am Soc Echocardiogr 2015;28:683-91.

31. Saeed IM, Coggins T, Main ML, Bateman TM. Cardiac sarcoidosis with visually normal wall motion: Role of cardiac MRI, FDG PET, and strain echocardiography. Eur Heart J Cardiovasc Imaging 2015;16:1275.

32. Tigen K, Sunbul M, Karaahmet T, Tasar O, Dundar C, Yalcinsoy M. Early detection of bi-ventricular and atrial mechanical dysfunction using two-dimensional speckle tracking echocardiography in patients with sarcoidosis. Lung 2015; 193:669-75.

33. Hyodo E, Hozumi T, Takemoto $\mathrm{Y}$, Watanabe $\mathrm{H}$, Muro $\mathrm{T}$, Yamagishi H. Early detection of cardiac involvement in patients with sarcoidosis by a non-invasive method with ultrasonic tissue characterisation. Heart 2004;90:1275-80.

34. Yasutake H, Seino Y, Kashiwagi M, Honma H, Matsuzaki T, Takano T. Detection of cardiac sarcoidosis using cardiac markers and myocardial integrated backscatter. Int $\mathrm{J}$ Cardiol 2005; 102:259-68.

35. Hourigan LA, Burstow DJ, Pohlner P, Clarke BE, Donnelly JE. Transesophageal echocardiographic abnormalities in a case of cardiac sarcoidosis. J Am Soc Echocardiogr 2001;14:399-402.

36. Nureki S, Miyazaki E, Nishio S, Ehara C, Yamasue M, Ando M. Interventricular septal thickening as an early manifestation of cardiac sarcoidosis. Int Heart J 2014;55:181-3.

37. Yazaki Y, Isobe M, Hayasaka M, Tanaka M, Fujii T, Sekiguchi M. Cardiac sarcoidosis mimicking hypertrophic cardiomyopathy: Clinical utility of radionuclide imaging for differential diagnosis. Jpn Circ J 1998;62:465-8.

38. Skold CM, Larsen FF, Rasmussen E, Pehrsson SK, Eklund AG. Determination of cardiac involvement in sarcoidosis by magnetic resonance imaging and Doppler echocardiography. J Intern Med 2002;252:465-71.

39. Youssef G, Beanlands RS, Birnie DH, Nery PB. Cardiac sarcoidosis: Applications of imaging in diagnosis and directing treatment. Heart 2011;97:2078-87.

40. Soejima K, Yada H. The work-up and management of patients with apparent or subclinical cardiac sarcoidosis: With emphasis on the associated heart rhythm abnormalities. J Cardiovasc Electrophysiol 2009;20:578-83.

41. Mehta D, Lubitz SA, Frankel Z, Wisnivesky JP, Einstein AJ, Goldman M. Cardiac involvement in patients with sarcoidosis: Diagnostic and prognostic value of outpatient testing. Chest 2008;133:1426-35.

42. Nishiyama Y, Yamamoto Y, Fukunaga K, Takinami H, Iwado Y, Satoh K. Comparative evaluation of ${ }^{18}$ F-FDG PET and ${ }^{67} \mathrm{Ga}$ scintigraphy in patients with sarcoidosis. $\mathrm{J}$ Nucl Med 2006;47:1571-6.

43. Treglia G, Annunziata S, Sobic-Saranovic D, Bertagna F, Caldarella $\mathrm{C}$, Giovanella L. The role of ${ }^{18}$ F-FDG-PET and PET/CT in patients with sarcoidosis: An updated evidence-based review. Acad Radiol 2014;21:675-84.

44. Ahmadian A, Brogan A, Berman J, Sverdlov AL, Mercier G, Mazzini M. Quantitative interpretation of FDG PET/CT with myocardial perfusion imaging increases diagnostic information in the evaluation of cardiac sarcoidosis. J Nucl Cardiol 2014;21:925-39.

45. Blankstein R, Osborne M, Naya M, Waller A, Kim CK, Murthy VL. Cardiac positron emission tomography enhances prognostic assessments of patients with suspected cardiac sarcoidosis. J Am Coll Cardiol 2014;63:329-36.

46. Koiwa H, Tsujino I, Ohira H, Yoshinaga K, Otsuka N, Nishimura M. Images in cardiovascular medicine: Imaging of cardiac sarcoid lesions using fasting cardiac ${ }^{18} \mathrm{~F}$-fluorodeoxyglucose positron emission tomography: An autopsy case. Circulation 2010;122:535-6.

47. Kubota R, Yamada S, Kubota K, Ishiwata K, Tamahashi N, Ido T. Intratumoral distribution of fluorine-18-fluorodeoxyglucose in vivo: High accumulation in macrophages and granulation tissues studied by microautoradiography. J Nucl Med 1992;33:1972-80.

48. Newsholme P, Newsholme EA. Rates of utilization of glucose, glutamine and oleate and formation of end-products by mouse peritoneal macrophages in culture. Biochem J 1989;261:211-8.

49. Dorbala S, Di Carli MF, Delbeke D, Abbara S, DePuey EG, Dilsizian V. SNMMI/ASNC/SCCT guideline for cardiac SPECT/ CT and PET/CT 1.0. J Nucl Med 2013;54:1485-507.

50. Jamar F, Buscombe J, Chiti A, Christian PE, Delbeke D, Donohoe KJ. EANM/SNMMI guideline for ${ }^{18} \mathrm{~F}$-FDG use in inflammation and infection. J Nucl Med 2013;54:647-58.

51. Morooka M, Moroi M, Uno K, Ito K, Wu J, Nakagawa T. Long fasting is effective in inhibiting physiological myocardial ${ }^{18} \mathrm{~F}$ FDG uptake and for evaluating active lesions of cardiac sarcoidosis. EJNMMI Res 2014;4:1. 
52. Scholtens AM, Verberne HJ, Budde RP, Lam MG. Additional heparin preadministration improves cardiac glucose metabolism suppression over low-carbohydrate diet alone in ${ }^{(1)(8)}$ F-FDG PET imaging. J Nucl Med 2015;57:568-73.

53. Yamagishi H, Shirai N, Takagi M, Yoshiyama M, Akioka K, Takeuchi K. Identification of cardiac sarcoidosis with ${ }^{(13)} \mathrm{N}$ $\mathrm{NH}_{(3)} /{ }^{(18)}$ F-FDG PET. J Nucl Med 2003;44:1030-6.

54. Ishimaru S, Tsujino I, Takei T, Tsukamoto E, Sakaue S, Kamigaki M. Focal uptake on ${ }^{18} \mathrm{~F}$-fluoro-2-deoxyglucose positron emission tomography images indicates cardiac involvement of sarcoidosis. Eur Heart J 2005;26:1538-43.

55. Okumura $\mathrm{W}$, Iwasaki T, Toyama T, Iso T, Arai M, Oriuchi N. Usefulness of fasting ${ }^{18} \mathrm{~F}$-FDG PET in identification of cardiac sarcoidosis. J Nucl Med 2004;45:1989-98.

56. McArdle BA, Birnie DH, Klein R, de Kemp RA, Leung E, Renaud J. Is there an association between clinical presentation and the location and extent of myocardial involvement of cardiac sarcoidosis as assessed by ${ }^{(1)(8)} \mathrm{F}$-fluorodeoxyglucose positron emission tomography? Circ Cardiovasc Imaging 2013;6:617-26.

57. Langah R, Spicer K, Gebregziabher M, Gordon L. Effectiveness of prolonged fasting ${ }^{18} \mathrm{~F}$-FDG PET-CT in the detection of cardiac sarcoidosis. J Nucl Cardiol 2009;16:801-10.

58. Tahara N, Tahara A, Nitta Y, Kodama N, Mizoguchi M, Kaida H. Heterogeneous myocardial FDG uptake and the disease activity in cardiac sarcoidosis. JACC Cardiovasc Imaging 2010;3:1219-28.

59. Osborne MT, Hulten EA, Singh A, Waller AH, Bittencourt MS, Stewart GC. Reduction in ${ }^{(1)(8)}$ F-fluorodeoxyglucose uptake on serial cardiac positron emission tomography is associated with improved left ventricular ejection fraction in patients with cardiac sarcoidosis. J Nucl Cardiol 2013;21:166-74.

60. Waller AH, Blankstein R. Quantifying myocardial inflammation using ${ }^{18} \mathrm{~F}$-fluorodeoxyglucose positron emission tomography in cardiac sarcoidosis. J Nucl Cardiol 2014;21:940-3.

61. Chapelon-Abric C, de Zuttere D, Duhaut P, Veyssier P, Wechsler B, Huong DL. Cardiac sarcoidosis: A retrospective study of 41 cases. Medicine (Baltim) 2004;83:315-34.

62. Le GD, Menad F, Faraggi M, Weinmann P, Battesti JP, Valeyre D. Myocardial sarcoidosis. Clinical value of technetium- $99 \mathrm{~m}$ sestamibi tomoscintigraphy. Chest 1994;106:1675-82.

63. Dilsizian V. Highlights from the updated joint ASNC/SNMMI PET myocardial perfusion and metabolism clinical imaging guidelines. J Nucl Med 2016;57:1327-8.

64. Holly TA, Abbott BG, Al-Mallah M, Calnon DA, Cohen MC, DiFilippo FP. Single photon-emission computed tomography. J Nucl Cardiol 2010;17:941-73.

65. Sciagra R, Passeri A, Bucerius J, Verberne HJ, Slart RH, Lindner O. Clinical use of quantitative cardiac perfusion PET: Rationale, modalities and possible indications. Position paper of the Cardiovascular Committee of the European Association of Nuclear Medicine (EANM). Eur J Nucl Med Mol Imaging 2016;43:153045.

66. Verberne HJ, Acampa W, Anagnostopoulos C, Ballinger J, Bengel F, De BP. EANM procedural guidelines for radionuclide myocardial perfusion imaging with SPECT and SPECT/CT: 2015 Revision. Eur J Nucl Med Mol Imaging 2015;42:1929-40.

67. Kapur A, Latus KA, Davies G, Dhawan RT, Eastick S, Jarritt PH. A comparison of three radionuclide myocardial perfusion tracers in clinical practice: The ROBUST study. Eur J Nucl Med Mol Imaging 2002;29:1608-16.

68. Berman JS, Govender P, Ruberg FL, Mazzini M, Miller EJ. Scadding revisited: A proposed staging system for sardiac sarcoidosis. Sarcoidosis Vasc Diffuse Lung Dis 2014;31:2-5.

69. Ohira H, Tsujino I, Ishimaru S, Oyama N, Takei T, Tsukamoto E. Myocardial imaging with ${ }^{18} \mathrm{~F}$-fluoro-2-deoxyglucose positron emission tomography and magnetic resonance imaging in sarcoidosis. Eur J Nucl Med Mol Imaging 2008;35:933-41.

70. Youssef G, Leung E, Mylonas I, Nery P, Williams K, Wisenberg G. The use of ${ }^{18}$ F-FDG PET in the diagnosis of cardiac sarcoidosis: A systematic review and metaanalysis including the Ontario experience. J Nucl Med 2012;53:241-8.

71. Okada DR, Bravo PE, Vita T, Agarwal V, Osborne MT, Taqueti VR. Isolated cardiac sarcoidosis: A focused review of an underrecognized entity. J Nucl Cardiol 2016 (Epub ahead of print).

72. Okumura W, Iwasaki T, Ueda T, Seki R, Miyajima A, Hatori T. Usefulness of ${ }^{18} \mathrm{~F}$-FDG PET for diagnosis of cardiac sarcoidosis. Kaku Igaku 1999;36:341-8.

73. Kramer CM, Barkhausen J, Flamm SD, Kim RJ, Nagel E. Standardized cardiovascular magnetic resonance (CMR) protocols 2013 update. J Cardiovasc Magn Reson 2013;15:91.

74. Orii M, Hirata K, Tanimoto T, Ota S, Shiono Y, Yamano T. Comparison of cardiac MRI and ${ }^{(18)}$ F-FDG positron emission tomography manifestations and regional response to corticosteroid therapy in newly diagnosed cardiac sarcoidosis with complete heart block. Heart Rhythm 2015;12:2477-85.

75. Kramer CM, Barkhausen J, Flamm SD, Kim RJ, Nagel E. Standardized cardiovascular magnetic resonance imaging (CMR) protocols, Society for Cardiovascular Magnetic Resonance: Board of Trustees Task Force on Standardized Protocols. J Cardiovasc Magn Reson 2008;10:35.

76. Greulich S, Deluigi CC, Gloekler S, Wahl A, Zurn C, Kramer U. CMR imaging predicts death and other adverse events in suspected cardiac sarcoidosis. JACC Cardiovasc Imaging 2013;6:501-11.

77. Nagai T, Kohsaka S, Okuda S, Anzai T, Asano K, Fukuda K. Incidence and prognostic significance of myocardial late gadolinium enhancement in patients with sarcoidosis without cardiac manifestation. Chest 2014;146:1064-72.

78. Patel AR, Klein MR, Chandra S, Spencer KT, Decara JM, Lang RM. Myocardial damage in patients with sarcoidosis and preserved left ventricular systolic function: An observational study. Eur J Heart Fail 2011;13:1231-7.

79. Smedema JP, Snoep G, van Kroonenburgh MP, van Geuns RJ, Cheriex EC, Gorgels AP. The additional value of gadoliniumenhanced MRI to standard assessment for cardiac involvement in patients with pulmonary sarcoidosis. Chest 2005;128:1629-37.

80. Smedema JP, Snoep G, van Kroonenburgh MP, van Geuns RJ, Dassen WR, Gorgels AP. Evaluation of the accuracy of gadoliniumenhanced cardiovascular magnetic resonance in the diagnosis of cardiac sarcoidosis. J Am Coll Cardiol 2005;45:1683-90.

81. Watanabe E, Kimura F, Nakajima T, Hiroe M, Kasai Y, Nagata M. Late gadolinium enhancement in cardiac sarcoidosis: Characteristic magnetic resonance findings and relationship with left ventricular function. J Thorac Imaging 2013;28:60-6.

82. Patel MR, Cawley PJ, Heitner JF, Klem I, Parker MA, Jaroudi WA. Detection of myocardial damage in patients with sarcoidosis. Circulation 2009;120:1969-77.

83. Murtagh G, Laffin LJ, Beshai JF, Maffessanti F, Bonham CA, Patel AV. Prognosis of myocardial damage in sarcoidosis patients with preserved left ventricular ejection fraction: Risk stratification using cardiovascular magnetic resonance. Circ Cardiovasc Imaging 2016;9:e003738.

84. Hulten E, Agarwal V, Cahill M, Cole G, Vita T, Parrish S. Presence of late gadolinium enhancement by cardiac magnetic resonance among patients with suspected cardiac sarcoidosis is associated with adverse cardiovascular prognosis: A systematic review and meta-analysis. Circ Cardiovasc Imaging 2016;9:e005001. 
85. Shimada T, Shimada K, Sakane T, Ochiai K, Tsukihashi H, Fukui M. Diagnosis of cardiac sarcoidosis and evaluation of the effects of steroid therapy by gadolinium-DTPA-enhanced magnetic resonance imaging. Am J Med 2001;110:520-7.

86. Yang Y, Safka K, Graham JJ, Roifman I, Zia MI, Wright GA. Correlation of late gadolinium enhancement MRI and quantitative T2 measurement in cardiac sarcoidosis. J Magn Reson Imaging 2014;39:609-16.

87. Murphy RC, Hammarstrom S, Samuelsson B. Leukotriene C: A slow-reacting substance from murine mastocytoma cells. Proc Natl Acad Sci USA 1979;76:4275-9.

88. Vignaux O, Dhote R, Duboc D, Blanche P, Dusser D, Weber S. Clinical significance of myocardial magnetic resonance abnormalities in patients with sarcoidosis: A 1-year follow-up study. Chest 2002;122:1895-901.

89. Ardehali H, Howard DL, Hariri A, Qasim A, Hare JM, Baughman KL. A positive endomyocardial biopsy result for sarcoid is associated with poor prognosis in patients with initially unexplained cardiomyopathy. Am Heart J 2005;150:459-63.

90. Ratner SJ, Fenoglio JJ Jr, Ursell PC. Utility of endomyocardial biopsy in the diagnosis of cardiac sarcoidosis. Chest 1986;90:528-33.

91. Kandolin R, Lehtonen J, Graner M, Schildt J, Salmenkivi K, Kivisto SM. Diagnosing isolated cardiac sarcoidosis. J Intern Med 2011;270:461-8.

92. Nery PB, Keren A, Healey J, Leug E, Beanlands RS, Birnie DH. Isolated cardiac sarcoidosis: establishing the diagnosis with electroanatomic mapping-guided endomyocardial biopsy. Can J Cardiol 2013;29:1015.e1-3.

93. Hamzeh NY, Wamboldt FS, Weinberger HD. Management of cardiac sarcoidosis in the United States: A Delphi study. Chest 2012;141:154-62.

94. Cain MA, Metzl MD, Patel AR, Addetia K, Spencer KT, Sweiss NJ. Cardiac sarcoidosis detected by late gadolinium enhancement and prevalence of atrial arrhythmias. Am J Cardiol 2014;113:1556-60.
95. Nadel J, Lancefield T, Voskoboinik A, Taylor AJ. Late gadolinium enhancement identified with cardiac magnetic resonance imaging in sarcoidosis patients is associated with longterm ventricular arrhythmia and sudden cardiac death. Eur Heart J Cardiovasc Imaging 2015; 16:634-41.

96. Ise T, Hasegawa T, Morita Y, Yamada N, Funada A, Takahama H. Extensive late gadolinium enhancement on cardiovascular magnetic resonance predicts adverse outcomes and lack of improvement in LV function after steroid therapy in cardiac sarcoidosis. Heart 2014;100:1165-72.

97. Betensky BP, Tschabrunn CM, Zado ES, Goldberg LR, Marchlinski FE, Garcia FC. Long-term follow-up of patients with cardiac sarcoidosis and implantable cardioverter-defibrillators. Heart Rhythm 2012;9:884-91.

98. Schuller JL, Zipse M, Crawford T, Bogun F, Beshai J, Patel AR. Implantable cardioverter defibrillator therapy in patients with cardiac sarcoidosis. J Cardiovasc Electrophysiol 2012;23:925-9.

99. Blankstein R, Waller AH. Evaluation of known or suspected cardiac sarcoidosis. Circ Cardiovasc Imaging 2016;9:e000867.

100. Hulten E, Aslam S, Osborne M, Abbasi S, Bittencourt MS, Blankstein R. Cardiac sarcoidosis-State of the art review. Cardiovasc Diagn Ther 2016;6:50-63.

101. Schneider S, Batrice A, Rischpler C, Eiber M, Ibrahim T, Nekolla SG. Utility of multimodal cardiac imaging with PET/ MRI in cardiac sarcoidosis: Implications for diagnosis, monitoring and treatment. Eur Heart J 2014;35:312.

102. Wada K, Niitsuma T, Yamaki T, Masuda A, Ito H, Kubo H. Simultaneous cardiac imaging to detect inflammation and scar tissue with F-fluorodeoxyglucose PET/MRI in cardiac sarcoidosis. J Nucl Cardiol 2015. doi:10.1007/s12350-015-0348-4.

103. Harisankar CN, Mittal BR, Agrawal KL, Abrar ML, Bhattacharya A. Utility of high fat and low carbohydrate diet in suppressing myocardial FDG uptake. J Nucl Cardiol 2011;18:926-36. 